University of Rhode Island

DigitalCommons@URI

Open Access Dissertations

1998

\title{
Adolescent Students with Behavior Disorders: Teacher's Current Referral Practices
}

Nancy Ruth Smith

University of Rhode Island

Follow this and additional works at: https://digitalcommons.uri.edu/oa_diss

\section{Recommended Citation}

Smith, Nancy Ruth, "Adolescent Students with Behavior Disorders: Teacher's Current Referral Practices" (1998). Open Access Dissertations. Paper 1068.

https://digitalcommons.uri.edu/oa_diss/1068

This Dissertation is brought to you for free and open access by DigitalCommons@URI. It has been accepted for inclusion in Open Access Dissertations by an authorized administrator of DigitalCommons@URI. For more information, please contact digitalcommons-group@uri.edu. 
ADOLESCENT STUDENTS WITH BEHAVIOR DISORDERS:

TEACHERS' CURRENT REFERRAL PRACTICES

BY

NANCY R. SMITH

A DISSERTATION SUBMITTED IN PARTIAL FULFILLMENT OF THE REQUIREMENTS FOR THE DEGREE OF

DOCTOR OF PHILOSOPHY

IN

PSYCHOLOGY 


\begin{abstract}
This study combined qualitative and quantitative methods to investigate teachers' practices when referring adolescent males and females to special education under the behavior disorder classification. Sixteen teachers were interviewed for the qualitative study. It was found that: teachers refer more males than females to special education for having a behavior disorder; females are more likely to be referred to guidance counselor as a means of addressing emotional/behavioral concerns within the school setting; within the classroom males tend to demonstrate more externalizing behaviors and females more internalizing behaviors; and teachers tend to demonstrate more leniency with females in the discipline process. In addition, two findings emerged from the interview process: teachers are aware that girls and boys manage their psychological difficulties in disparate ways, girls seek help from their peer group and guidance counselors whereas males are much less likely to verbalize their difficulties; and teachers perceive girls as managing their psychological difficulties in ways that enable them to obtain support for their problems. For the quantitative study, 60 teachers completed a modified version of the Achenbach Teacher Report Form that contained scales associated with the Internalizing and Externalizing factors. Results indicated that: males experiencing psychological difficulties demonstrate significantly more externalizing behaviors than females experiencing psychological difficulties; males experiencing psychological difficulties demonstrate significantly more externalizing behaviors than males referred to special education for having a behavior disorder; females experiencing psychological difficulties demonstrate significantly more internalizing behaviors than males experiencing psychological difficulties; and males referred to special education demonstrate significantly more internalizing behaviors than males who are experiencing psychological difficulties. The quantitative results indicate that teachers utilize a gender neutral set of criteria when referring students to special education for a behavior disorder. Consequently, females who
\end{abstract}


demonstrate internalizing behaviors may be overlooked within the current formal special education referral system. 
This dissertation emerged from years of support provided by professors, colleagues, friends, and family. Many thanks to my committee members Janet Kulberg and George Willis who provided me with professional guidance and support as I engaged in the research and writing process. John Stevenson, my Major Professor, was extremely helpful in offering emotional support as I struggled with logistics, statistics, and theoretical issues. His consistent support and rigorous examination of my work forced me to push the boundaries of my knowledge and challenged me to reconceptualize my research. Greg Norman provided statistical consultation throughout the research process, assisting in the design and interpretation for the quantitative study. Grace Ashton was an integral part of the research and writing process, offering emotional support and critical feedback over the course of a few years. Susan Smith Robbins and John Smith often lent a sympathetic ear and reminded me that life consists of more than graduate school and one's dissertation. Many thanks to Liz Dufresne for her assistance with logistical matters.

Most importantly, I would like to thank my parents John and Florence Smith.. Their unconditional support has enabled me to persevere through my graduate studies. This dissertation reflects their commitment to providing me with the opportunity to pursue my goals. I was able to push myself to reach my full potential due to their unwavering dedication to my education. Mom and Dad, thanks for giving me the confidence to prove Ms. Leopold wrong. 


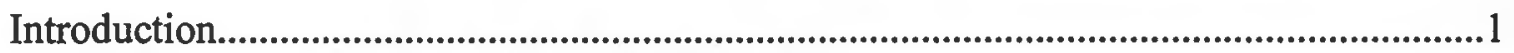

Behavior Disorders: Current Federal Definition......................................................2

Internalizing vs. Externalizing Disorders...................................................................

Teachers' Referral Practices................................................................................6

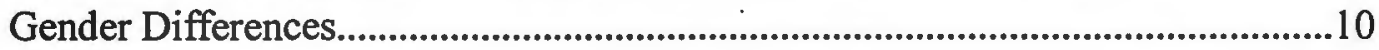

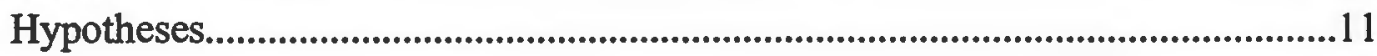

Study \#1

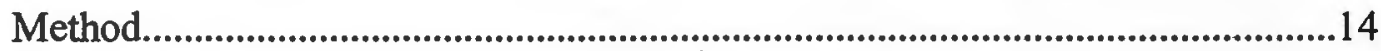

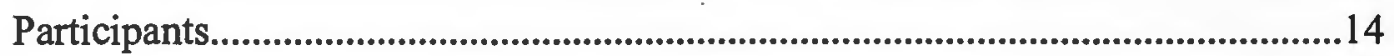

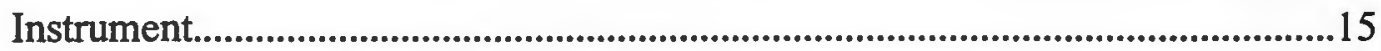

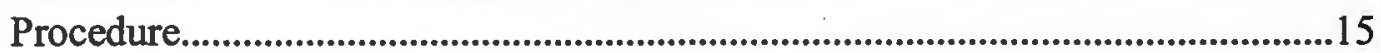

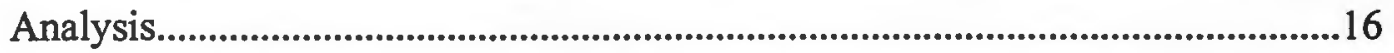

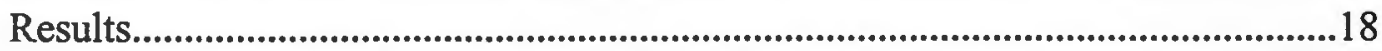

Current school programs..................................................................................18

Referring students for behavior issues.................................................26

Variation in teachers' referral practices......................................................28

"Typical" characteristics of students with behavior disorders......................32

Benefits of referring a student to special education.......................................40

Students who "fall through the cracks".......................................................43

Internalizing and externalizing behavior: Relation to gender......................47

Study \#2

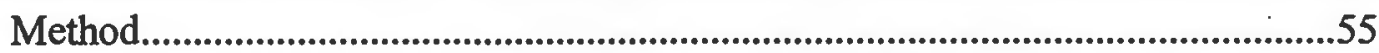

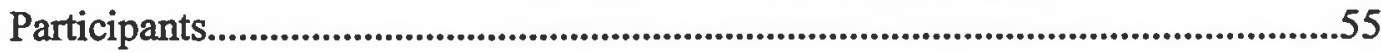

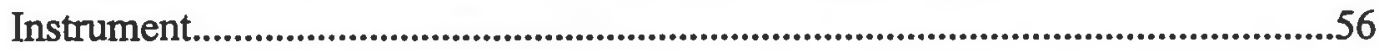

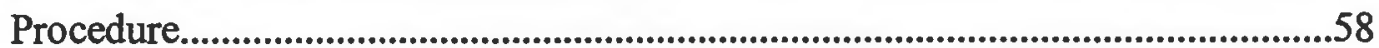

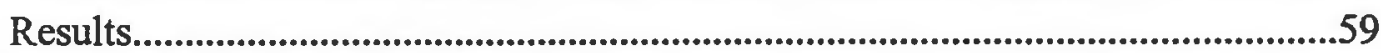

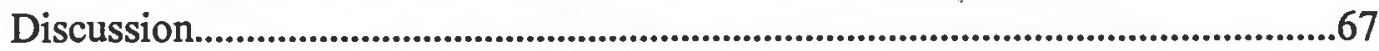

Discussion of Results from Both Studies...........................................................................

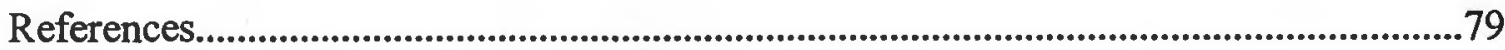

Appendix A: Outline of Teacher Interview ...........................................................................8.

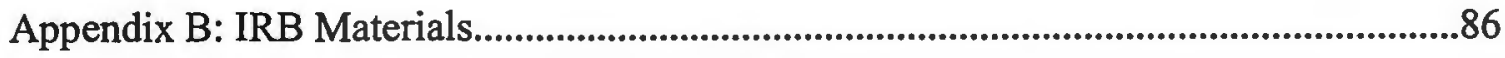

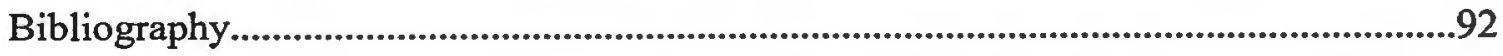




\section{List of Tables}

Table \#1: Subjects taught by teachers interviewed. 14

Table \#2: Subjects taught by teachers completing questionnaires. .56

Table \#3: Means and standard deviations on questionnaires: Scores for females on subscale and factor scores. 60

Table \#4: Means and standard deviations on questionnaires: Scores for males on subscale and factor scores.

Table \#5: Mean scores of male and female teachers on subscale and factor scores. .64

Table \#6: Standardized $\underline{\mathrm{t}}$ scores for males on internalizing and externalizing factors. 64

Table \#7: Standardized $\mathrm{t}$ scores for females on internalizing and externalizing factors. .65

Table \#8: Correlations between subscale and factor scores .66 


\section{List of Figures}

Figure \#1: Externalizing Behaviors: Comparing males and females on referral and

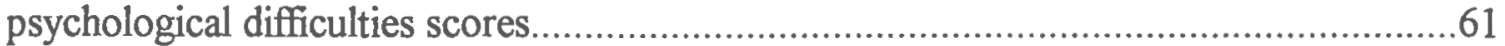

Figure \#2: Internalizing Behaviors: Comparing males and females on referral and psychological difficulties scores. .62 


\section{INTRODUCTION}

This study investigates why significantly more adolescent males than females are referred for special education services under the behavior disorder classification. It is hypothesized that teachers refer students with externalizing behaviors (conduct, oppositional and attention deficit behaviors) as having a behavior disorder (BD) more often than students with internalizing behaviors (depression and anxiety). Teachers find externalizing behaviors more disruptive than internalizing behaviors (Algozzine, 1977; Epstein, Kauffman, \& Cullinan, 1985) within the context of mainstream educational settings. The more disturbing a teacher finds a student's behavior to be, the more likely the student will be referred for BD services (Algozzine, Ruhl, Ramsey, Wood, Phillips, Maheady, Skiba, Best, Cooke, \& Walker, 1991).

Among children referred for mental health services, Achenbach, Howell, Quay and Connors (1991) determined that girls experiencing psychological difficulties during adolescence are more likely to demonstrate internalizing disorders while males are likely to demonstrate externalizing disorders. Males and females, therefore, manifest their psychological difficulties in disparate ways that are related to gender.

Currently, only $23.6 \%$ of all secondary aged students classified as having a behavior disorder are female (National Longitudinal Transition Study, 1992). Within the literature, researchers have reported male/female ratios ranging from 3:1 to 25:1 (Callahan, 1994; Hayden-McPeak, Gaskin, \& Gaughan, 1993; Jennings, Mendelsohn, May, \& Brown, 1988; Stockard, 1980). The disparity between the number of males and females provided with services through the behavior disorder classification does not correspond with base rates for childhood psychopathology. Achenbach and Edelbrock (1981) and Achenbach et al. (1991) determined that prevalence rates for childhood psychological disturbances are comparable for boys and girls in normative samples aged 4-16. It is unclear why males receive special education services for behavior disorders at 
a ratio of three to one when females demonstrate generally equivalent rates of childhood psychopathology as males.

One probable explanation is that current referral procedures may not be recognizing and addressing the unique characteristics of adolescent females experiencing psychological distress. As Algozzine et al. (1991) state, "Female students or those exhibiting withdrawn, internalizing behavior that is not disruptive, distracting, or bothersome go largely unreferred" (p. 14). It is crucial to inspect current educational practices because: ..." a highly disparate sex ratio raises questions about the larger, more general issue of faimess and equity in the delivery of specialized services to boys and girls in public schools" (Callahan, 1994, p. 228-229).

\section{Behavior Disorders: The Current Federal Definition}

The current federal definition for the behavior disorder classification specifies which types of students are eligible for special education services and clearly delineates the types of behaviors that are considered necessary to qualify for special education services as seriously emotionally disturbed (the category equivalent to the Rhode Island classification of behavior disorder and the Maine classification of behavior impairment). Within this paper, the term behavior disorder will be used to denote students receiving who are referred to, receiving, or under consideration for special education services on the basis of their behavior. The federal definition states:

The term means a condition exhibiting one or more of the following characteristics over a long period of time or to a marked degree, which adversely affects educational performance:

a. An inability to learn which cannot be explained by intellectual, sensory, or health factors;

b. An inability to build or maintain satisfactory interpersonal relationships with peers and teachers;

c. Inappropriate types of behavior or feelings under normal circumstances;

d. A general pervasive mood of unhappiness or depression; or 
e. A tendency to develop physical symptoms or fears associated with personal or school problems.

The term includes children who are schizophrenic. The term does not include children who are socially maladjusted, unless it is determined that they are seriously emotionally disturbed (U.S. Department of Education, 1990).

This definition clearly specifies that the classification is conceptualized to meet the needs of students demonstrating both internalizing and externalizing behaviors. Specifically, two categories focus on the manifestation of internalizing behaviors (i.e., pervasive feelings of depression and somatization), elucidating a policy designed to meet a broad band of behaviors.

\section{Internalizing vs. Externalizing Disorders}

Research has indicated that the two main categories of internalizing and externalizing behavior problems exist for children across all age groups for normal and behaviorally impaired children (Achenbach \& Edelbrock, 1983). Achenbach and Edelbrock state that externalizing disorders are characterized by aggression, hyperactivity, cruelty, delinquency, destructiveness, disruptiveness and similar problems that involve acting out against the environment. Cullinan, Epstein, and Lloyd (1983) state that an externalizing disorder is an "environmental conflict - behavior that irritates, harms, disrupts, or otherwise puts the child into conflict with individuals or groups in his or her environment" (p. 129).

Internalizing disorders are characterized by anxiety, depression, shyness, social withdrawal, somatic complaints, and self-consciousness (Achenbach \& Edelbrock, 1983). These disorders may be described as a "personal disturbance - behavior that concerns others because it interferes with the child's personal development and/or indicates serious emotional distress" (Cullinan, et al., 1983, p. 129). Individuals demonstrating internalizing disorders tend to isolate themselves from the external world. According to Achenbach (1991), narrow band factors that constitute the broad band Internalizing factor are anxious/depressed behavior, withdrawal, and somatic complaints. 
The nature of behavior problems appear to vary by sex, with adolescent boys exhibiting more externalizing disorders and adolescent females exhibiting more internalizing disorders in students referred for mental health services (Cullinan et al., 1983). In comparing the adjustment problems in elementary and secondary aged students, Cullinan, Epstein and Kauffman (1984) found that "males were more likely (than females) to be rated as showing problems having to do with aggressive, acting out behavior" ( $p$. 16). MacFarlane et al. (1954) also found that "Boys were more likely to have problems that irritated, disrupted, or otherwise involved conflict with persons in the environment whereas girls tended to show problems involving personal conflict or distress that were not particularly disruptive "(cited in Cullinan, Epstein, \& Lloyd, 1983). Thus, adolescents experiencing psychological difficulties are likely to demonstrate their psychological difficulties in ways highly related to gender. These differences between males and females may be based upon the manifestation of gender role stereotypes during childhood and adolescence.

Brown and Gilligan (1992) report that both males and females undergo periods of psychological trauma as sex role expectations are identified, understood, and incorporated into one's behavioral repertoire. In describing this process, Brown and Gilligan (1992) state:

On a theoretical level, the evidence we gathered led us to consider early adolescence as a comparable time in women's development to early childhood in men's: a time when a relational impasse forced what psychoanalysists have called "a compromise formation"-some compromise between voice and relationships. Because this compromise removes or attenuates the tension between women's voices and the regeneration of patriarchal and male-voiced cultures, it tends to be seen as necessary and inevitable. In fact, it leaves a psychological wound or scar, a break manifest in the heightened susceptibility to psychological illness that boys suffer in early childhood and that girls suffer at adolescence (pp 218-219).

Brown and Gilligan provide a clear and careful explanation for two particular points in time when individuals face crises as a result of confronting and conforming to societal expectations regarding sex role norms. Through this process individuals learn how to live 
as members of either gender. Development includes the task of understanding how one is to act, interact, and behave within the confines of sex role stereotypes. This process of conforming results in individuals learning how they may express their feelings, and the behaviors that may be demonstrated in this process. The socialization process encourages males to stifle their emotions, minimizing the need for emotional support from others, as suggested by Brown and Gilligan's mention of the crisis males face as they separate and individuate from their mothers. As a result, males may tend to demonstrate externalizing behaviors that allow them to demonstrate their feelings through non-verbal means. Females, on the other hand, are taught to maintain a focus on relationship, as suggested by Gilligan and Brown's finding that adolescent females tend to maintain a primary focus on relationships, resulting in a "loss of voice." This may result in the manifestation of internalizing behaviors by females.

The difference between the number of internalizing and externalizing behaviors demonstrated may reflect the differential pattern of ego development for adolescent boys and girls. Hauser, Jacobson, Noam and Powers (1983) as well as Redmore and Loevinger (1979) concluded that girls tend to function at a higher level of ego development than boys during adolescence. This differential level of ego development, therefore, may provide insight as to why males and females utilize differential coping strategies as a means of managing perceived difficulties.

Specifically, Noam and Borst (1994) concluded that individuals operating from a pre-conformist perspective "present as overtly angry, impulsive, and concrete, and have great difficulty taking the perspective of other people" (p. 45). Within this orientation, externalizing defenses, such as displacement, regression, and identification with the aggressor are utilized (Noam \& Borst, 1994). It is possible that adolescent males may be operating from within this perspective, resulting in the manifestation of a greater number of externalizing behaviors. 
According to Noam and Borst (1994), individuals operating from a conformist perspective tend to internalize more of their difficulties and demonstrate greater levels of self-blame and depression. Defenses utilized by conformist individuals tend to focus on internalizing behaviors, such as denial, reaction formation, intellectualism, rationalization, and isolation of affect. (Noam \& Borst, 1994). Gender related differences, therefore, may reflect differential levels of ego development. These gender based differences may have a significant impact on how the behaviors of individuals are perceived and addressed within the context of mainstream educational settings.

\section{Teachers' Referral Practices}

In order to receive special education services, students must first be referred by a teacher or other school personnel. Algozzine, Christenson and Ysseldyke (1982) found that from $75 \%$ to $90 \%$ of initial referrals result in a special education classification. In the eligibility determination process, the information that had the most influence over the eligibility determination was provided by the regular education teacher (Ysseldyke \& Thurlow, 1984). Teachers' knowledge bases and practices, therefore, are crucial in determining which students will receive special education services.

A substantial amount of literature has focused upon the difficulties inherent in referring, identifying, and classifying students for special education categories. Social critics have argued that special education classifications are socially constructed and vary considerably from state to state, from district to district, and from school to school, resulting in referrals and identifications made on non-quantifiable and judgmental criteria (Edgar \& Hayden, 1985). Borko and Caldwell (1982) found that teachers' decision policies were "essentially idiosyncratic," teachers utilized a plethora of decision making strategies when attending to student behavior. In addition, the gender, race, socioeconomic level, and intelligence quotient of the individual providing the referral may influence the identification process (Achenbach \& Edelbrock, 1983; Kauffman, Swan, \& 
Wood, 1980; Miller, 1972). Teachers' perceptions of special education terms may also be influenced by students' race, students' socioeconomic level, and the gender of the students (Vitale, 1983). The referral process, therefore, appears to be highly subjective and situation based.

Wood (1981) concluded that "the labeling process as it unfolds in schools is much more influenced by subtle social and political factors than many teachers realize" (p. 53). In the referral practice, Wood hypothesized that the following process is employed:

1. Thought- Student's behavior is disturbing to teacher

2. Teacher Value Judgement I- Based on observation of student's behavior.

3. Act- His or her behavior is disordered. Student is a behavior problem.

4. Thought- Why does the student behave in a disordered, disturbing way?

5. Teacher Value Judgement II- Made on inferences about students' cognitive/emotional state based on observation of the students' behavior.

6. Act- student classified as Socially-Emotionally Disturbed or BD (p.56)

Wood's decision tree reflects how the teachers' understanding of behavior occurs within the context of their value system. In the referral and classification process, teachers utilize internal standards to determine how a student's behavior is perceived to differ from the behavior of their peers. Inherent in these value systems are cultural norms and constructs. These societal constructs mediate one's value system and determine which behaviors are considered to be acceptable and which are aberrant within the environment.

Ecological theorists have proposed that a child's perceived behavior disorder is the result of an interaction between the child's behavior and the ecosystem the child is currently functioning within (Algozzine, 1977, Rhodes, 1967, 1970; Rhodes \& Paul, 1978). As Algozzine (1977) states:

It seems... that it is not simply the level and type of behavior that a child exhibits which may result in being identified as "disturbed," but the fact that particular set of characteristics which make him/her an individual results in differential reactions (or degrees of disturbingness and intolerance) from others within the child's ecosystem (p. 112). 
A key component of Algozzine's explanation of a behavior disorder is the teachers' perceived reaction to how "disturbing" the behavior is within the context of the classroom. An understanding of the child's behavior is based upon how it is perceived and understood by those in positions of power within the ecosystem. If individuals are demonstrating maladaptive behaviors that are not disruptive, they may be much less likely to be viewed as a behavior "problem."

According to Shinn (1987) teachers' referral practices may represent a wish to reduce the variance of students within their classrooms. Shinn equates teachers' practices with an economics of teaching resources:

In this micro-economic analysis, teachers are hypothesized to have two methods of increasing their teaching effectiveness. One is to increase the teaching resources, in most cases a "non-option." The other is to refer deviant performing students so that the teacher's limited resources can be applied to those who profit within the resources available (p. 39).

Students who demonstrate acting out/aggressive behaviors are likely to be referred to special classes (Kauffman, McCullough \& Sabornie, 1985). This practice may occur because teachers report that externalizing disorders are the most problematic and threatening to their classroom environment. Out of a list of 55 behaviors presented on the Behavior Problem Checklist, Junior High School teachers rated the top ten disturbing behaviors as destructiveness; disruptiveness; disobedience; negativism; stealing in the company of others; fighting, boisterousness, rowdiness; temper tantrums; irritability, easily aroused to anger; and impertinence, sauciness (Mullen \& Wood, 1986). Overall, teachers were most disturbed by behaviors classified as socially defiant and acting out behaviors.

Martin (1972) determined that in a study of 80 subjects in second grade classrooms, teachers engaged in almost twice as many contacts with "problem behavior" boys as they did with nonbehavior problem boys, nonbehavior problem girls, or girls with "behavior problems." In Martin's study, five teachers provided lists of students in their 
classrooms, rank ordering the students from nonbehavior problem children to behavior problem children. Eight nonbehavior problem children and eight behavior problem students were observed in each classroom with the researchers noting didactic student/teacher interactions. According to Martin's findings, if a male and a female both demonstrate a "problem behavior" within a classroom setting, it is likely that the male will receive considerably more attention and contact with the teacher. Martin hypothesizes that, ..." problems exhibited by girls do not demand the immediate attention of the teacher that is required in the more disruptive categories of problems" (p. 345). It is suggested that externalizing behaviors are most disturbing to teachers because they directly challenge teachers' authority within the classroom setting (Mullen \& Wood, 1986).

Pearcy, Clopton, and Pope (1993) determined that children with externalizing disorders are referred for mental health services more often than children with internalizing disorders, and that externalizing problems may be more salient in teachers' recollections than internalizing disorders. When inspecting referral practices in relation to internalizing versus externalizing disorders, Pearcy et al. found surprising results:

... as the severity of externalizing problems increased from the nondisorder to the disorder level, referral increased; but as the severity of internalizing problems increased from the nondisorder level to the disorder level, referral decreased (p. 167).

Teachers are accurately recognizing that an increase in externalizing behavior may be clinically significant and appear to be referring students at appropriate rates. Teachers, however, may fail to recognize the severity and negative implications of internalizing disorders and appear to be overlooking clinically significant behaviors. Pearcy et al. speculate that teachers may not be able to closely monitor all of the children in a busy classroom, resulting in behaviors such as depression and social withdrawal to be overlooked more often than hyperactivity or aggression. In addition, an increase in externalizing behaviors means higher levels of student disruption in the classroom. On the other hand, students who demonstrate higher levels of internalizing behaviors tend to 
become increasingly more withdrawn and isolated from the external world, placing fewer and fewer demands on the teacher as they grow more detached. As a result, ..." teachers are spontaneously identifying some, but not all, students with behavior problems, being more likely to identify students who exhibit externalizing behaviors " (Algozzine et al., 1991).

\section{Gender Differences}

Epstein, Kauffman, and Cullinan (1985) administered the Behavior Problem Checklist to teachers in order to compare the types of characteristics which were most reflective of students with behavior disorders in males and females, aged 12-18. The factors found for both boys and girls were Aggression-Disruption, Social Maladjustment, Anxiety-Inferiority, and Attention Deficit. The Depression factor was found to be unique for females aged 12-18, indicating that secondary teachers recognize at least one aspect of differential adolescent female functioning. Social Incompetence was also found to be a factor that differentiated secondary aged boys from secondary aged girls; teachers indicated that social incompetence, which included social withdrawal, shyness, reticence, drowsiness, and passivity, was indicative of a problem in adolescent males. It is important to note that teachers only specified one type of internalizing behavior (i.e. depression) as being a "typical" characteristic of adolescent females with behavior disorders.

Consequently, (with the exception of the depression factor), teachers described that females demonstrating behavior disorders generally demonstrate externalizing behaviors. Female students demonstrating internalizing disorders were not considered "typical" students with behavior disorders.

Mattison, Morales, and Bauer (1991) found that adolescent females (both classified as behaviorally impaired and not classified as behaviorally impaired) demonstrated a tendency to exhibit internalizing disorders. Students classified as being behaviorally impaired had been referred to special education and were classified under the behavior disorder category. For secondary aged females, $55 \%$ of behaviorally impaired 
females exhibited internalizing disorders while $75.2 \%$ of non-behaviorally impaired females exhibited internalizing disorders. Significantly more non-special education females exhibited internalizing disorders than referred females. In addition, $35 \%$ of behaviorally impaired females exhibited externalizing disorders, compared with $12.5 \%$ of non-behaviorally impaired females. Thus, on the whole, more female adolescents demonstrated internalizing disorders as opposed to externalizing disorders. It appears that the presence of externalizing behaviors substantially increases the probability of a female being referred for special education services and classified as having a behavior disorder.

Adolescent females, therefore, may be invisible due to the passivity and silence of their difficulties as compared to the open defiance and aggression of their male peers. Mullen and Wood (1986) found that shyness, bashfulness; aloofness, social reserve; social withdrawal; and lack of self-confidence were among the ten least disturbing behaviors described by teachers. As Algozzine et al. (1991) state, "Female students or those exhibiting withdrawn, internalizing behavior that is not disruptive, distracting, or bothersome go largely unreferred" (p. 14).

\section{Hypotheses}

\section{Qualitative Areas of Exploration}

The following topics were seen as a starting point for the qualitative inquiry: teachers descriptions of their attitudes around the BD classification; an understanding of teachers' current referral practices for BD services; an understanding of how the BD classification is socially constructed in the school setting; the function of the BD classification within the school system; insight into teachers' perceived benefits of referring students for BD services; an understanding of the types of students teachers report are currently referred for BD services; an overview of teachers' perceptions of non-special education services that may be provided to students experiencing psychological distress in school settings; an exploration of teachers' understandings of 
differential behaviors for males and females experiencing psychological distress; and an overview of behaviors found to be most disturbing by classroom teachers.

\section{Quantitative Hypotheses}

It is hypothesized that teachers will report that adolescent females demonstrate different behaviors than adolescent males when experiencing psychological distress. It is predicted that: teachers will report that when experiencing psychological distress, boys demonstrate higher levels of externalizing behaviors than internalizing behaviors; teachers will report that girls demonstrate higher levels of internalizing than externalizing behaviors when experiencing psychological distress; and when experiencing psychological distress, girls demonstrate higher levels of internalizing behaviors than boys, and boys demonstrate higher levels of externalizing behaviors than girls.

It is hypothesized that teachers will report no gender differences in the behaviors leading to a special education referral for a behavior disorder. It is predicted that: boys will be referred more often for externalizing than internalizing behaviors; girls will be referred more often for externalizing than internalizing behaviors; and no significant gender based differences will be reported for behaviors leading to a BD referral.

It is hypothesized that a gender based difference exists in the relationship between behaviors indicative of psychological distress and behaviors likely to lead to a BD referral, as perceived by teachers. It is predicted that: behaviors indicative of psychological distress in males are also the behaviors that precipitate a $\mathrm{BD}$ referral; and the behaviors indicative of psychological distress in females are not the behaviors that lead to a BD referral.

This study utilizes two methodologies to explore current practices in school settings. First, a single site qualitative case study is used to explore current referral practices. A qualitative approach is utilized in order for the researcher to gain an understanding of how teachers are presently understanding and responding to students' behaviors within classrooms. The qualitative approach makes it possible for the researcher 
to form an understanding of internalizing and externalizing behavior that is grounded in teachers' perceptions. In addition, the researcher considers it crucial to frame the quantitative research question taking into account the perspective of classroom teachers. It is important to understand the challenges classroom teachers face as they attempt to manage large classrooms of students with limited resources. An understanding of current practices grounded in teachers' perceptions, therefore, allowed the researcher to investigate the research question from a viewpoint that was respectful of the complexities and limitations of the current system.

The quantitative study was used as a follow up procedure to the qualitative portion of the study. The quantitative study utilized questionnaires to assess teachers' current referral practices in a standardized manner. Specifically, the quantitative portion of the study was used to investigate: which behaviors teachers feel are typical of adolescent males experiencing psychological difficulties (i.e. internalizing and externalizing behaviors); which behaviors are typical of adolescent females experiencing psychological difficulties; and significant differences between teachers' perceptions of the behaviors demonstrated by males and females experiencing psychological difficulties. In addition, the quantitative portion of the study investigated the behaviors which would lead to a special education referral under the BD classification for males; the behaviors that would lead to a BD referral for females, and differences existed between males and females in the manifestation of these behaviors. The quantitative portion of the study: extended the research question across a larger number of individuals and two sites to investigate how teachers understand and respond to the behavior of males and females in mainstream educational settings; utilized standardized data, and provided for the quantitative precision of analysis. 


\section{STUDY \#1}

\section{Method}

\section{Participants}

Permission to conduct research was obtained from the superintendent of schools in a rural Maine district. Interviews were conducted at the middle school, which serves 1100 sixth, seventh, and eighth graders and employs 60 teachers. Less than one percent of students are members of minorities.

The researcher attended a faculty meeting at the school where teachers were asked to volunteer to participate in a 45 minute interview. Teachers were given a form to indicate their willingness to participate in the study. Teachers not at the meeting were asked to participate individually at a later time. From the 21 teachers who indicated their willingness to participate, 16 teachers were randomly selected ( 8 male and 8 female) and individual interviews scheduled.

Table \#1

Subjects Taught by Teachers Interviewed

\begin{tabular}{ll}
\hline Subject & Number of Teachers Interviewed * \\
Science & 5 \\
Social Studies & 5 \\
Language Arts & 5 \\
Math & 4 \\
Consumer Science & 2 \\
Industrial Arts & 1 \\
Physical Education & 1
\end{tabular}

Totals are greater than sixteen. Most individuals teach more than one subject.

Permission to conduct research was obtained through the Institutional Review Board at the University of Rhode Island. For a copy of the IRB consent to conduct research form, and consent forms signed by those interviewed, please refer to Appendix C. 


\section{Instrument}

The researcher conducted a semi-structured interview, using the general interview protocol in Appendix A. The interview explored: teachers' understandings of "typical" students with behavior disorders; "red flag" behaviors that indicate that students present with a behavior disorder; current practices when referring students to special education under the BD classification; "problem" behaviors most likely to result in a BD referral; benefits of referring a student to special education; students who may be overlooked by the current system; differential "problem" behaviors of males and females; perceived school- based definition of students with behavior disorders; and support systems in place for students experiencing psychological difficulties in the school setting. Demographic information was obtained and kept separate from the written record of the interview.

\section{Procedure}

Interviews were conducted before school, after school, or during teachers' free periods. The researcher contacted teachers individually and arranged interview times. At the individual interview, the researcher explained and obtained informed consent to conduct and audiotape the interview.

The questions contained in the semi-structured interview were seen as a starting point for inquiry. The researcher asked questions and pursued lines of questioning based upon teachers' responses: a process founded upon methodological hermeneutics, where responses are constantly contextualized and understood as existing within a larger whole (Woolfolk, Sass, \& Messer 1988). Methodological hermeneutics is centered on a process of ongoing contextualization that results in the "hermeneutic circle" where parts (i.e., specific explanations for a phenomenon) are seen as existing in a larger whole, while the whole is understood as the sum of parts that are interrelated and changing. The interview process was fundamentally considered a dialogue where the researcher's questions were directly tailored to the content of the teacher's reply. Thus, the "whole" (the researcher's 
understanding of the questions being asked) was constantly affected by the parts (teachers' responses). As the researcher's understanding of the "whole" shifted based upon information presented, the questions asked of the teachers shifted to reflect this new understanding. This approach allowed the researcher the freedom to: explore themes raised by the individual being interviewed more in-depth, clarify and expand upon responses, as well as pursue lines of inquiry that had not been contained in the researcher's original conceptualization of the research issues. The interviews, therefore, were seen as dynamic forces that shaped the researcher's perspective and then informed subsequent interviews conducted.

Though the questions contained in the semi-structured interviews were generally asked of all teachers, the researcher used an idiosyncratic approach that elucidated and expanded upon themes raised by the teachers, as well as clarified descriptions. During the interviews, the researcher attempted to ask balanced questions about both genders so that the teachers would not feel the need to "fit" their replies to the researchers' expectations.

\section{Analysis}

The qualitative analysis conducted was designed to provide a rich, detailed picture of how the teachers understood their students' behaviors, the referral process, and consequences of referring a student to special education under the BD classification. Upon the completion of all interviews, each interview was transcribed into a word processor program in its entirety by the researcher. Qualitative analysis focused on elucidating underlying themes and formulating appropriate codes (Miles \& Huberman, 1994). The researcher used a grounded approach, meaning that codes were formulated only after the complete text had been read through. An inductive approach allowed themes to emerge instead of engaging in a process of "fitting" the text to a set of predetermined, prescribed codes. The coding process corresponded with the interview method, in that teacher's were given a semi-structured interview so that they could provide 
their insight and understanding of the referral process, allowing codes to be formulated in after the interview process was complete. Teacher's responses were then all read through in their entirety and commonalities as well as differences noted.

The researcher obtained a comprehensive understanding of the content of each interview through the transcription process. The researcher then read through the transcripts, attempting to view all interviews as a unified body of text. After the researcher read through the text a second time, descriptive codes were written. The descriptive codes were read through, and pattern codes formed. The interviews were then read through again, using different colored pens to note responses which corresponded with various pattern codes. Pattern codes are defined by Miles and Huberman (1994) as ..." a way of grouping ... summaries into a small number of sets, themes, or constructs" (p. 69). The pattern codes summarized themes, explanations, relationships among people, and theoretical constructs. Pattern codes were then written on the top of index cards, and corresponding responses written in their entirety under them. The results were written by organizing the information contained under each pattern code in a way that corresponded with the researcher's theoretical understanding of the research issue. Thus, the subheadings in the results section represent a pattern code, and the subsequent analysis represents the researcher's organization of the data.

The qualitative analysis fundamentally maintained an interpretative stance. The viewpoints, biases, history, and belief system of the researcher were considered integral aspects of the questions being asked and the means of understanding the teachers' responses (Packer \& Addison, 1989). The goal of the investigation was not to find causal relationships between variables, but rather to provide an in-depth exploration of a specific phenomenon within the context of a limited number of schools. Thus, the results of the investigation are considered to be a carefully constructed understanding of the phenomenon under investigation that reflects the unique characteristics of the researcher, the sites under investigation, and the individuals being interviewed. 


\section{Results}

\section{Current School Programs}

Throughout the interviews, teachers were asked to describe school programs currently in place designed to meet the behavioral needs of students. The interviewer intentionally did not define "behavior disorder," "problem behaviors" or "psychological difficulties" in the hope that teachers' answers would provide insight into which types of behaviors were of most concern within the school setting.

All of the teachers interviewed provided a description of the Boost program. Boost is a non-special education program designed to assist "kids who are having problems with their behaviors in content areas." The purpose of Boost is described as "to help students with serious behavioral difficulties succeed in the regular classroom. A short term placement that attempts to address students' behavioral issues before they are referred to special education, it aims to return its students to the mainstream as soon as possible" (teacher reading from Boost program description). Boost is a self-contained classroom for sixth, seventh, and eighth graders designed to provide a short term placement for students whose behavioral needs negatively impact their ability to be successful in a mainstream setting. The Boost program is designed to be a short term placement (with optimal placement time reported by teachers as 6-8 weeks) where students are placed in a small group setting with a teacher and an aide for academic instruction. The Boost program focuses on behavioral issues while providing tutoring and academic support in content areas from the Boost teacher and aide. One teacher provides her understanding of the purpose of Boost as:

a chance to get away from (their relationship with kids), to work in a smaller group, to look at how to deal with confrontations with other kids. a lot of the processing that is necessary when the kids are having problems is easily done when you have two teachers for, let's say, eight kids.

In addition, Boost is described as an opportunity for kids to "Boost their academics." 
The Boost program is structured so that the team members work closely with the student while in Boost by providing the academic work completed in the team during the student's absence. In addition, teachers from each team are expected to visit with the student and teacher of the Boost program at least once a week to facilitate communication. Students may be placed for the full day, or a few periods per day. Students then may return to their teams by being "mainstreamed" back in one period at a time. According to teacher report, "They go, get their fix, and are then worked back into the program. Attend a class at a time." As part of the "mainstreaming" process, students sign a behavior contract with the Boost teacher outlining their commitment to changing their behaviors which made them originally unsuccessful in their mainstream program, "(the teacher) made a contract with each of the kids, they sign it... and if they don't follow that, then they have to go back down to the Boost room until they are ready to fulfill their commitments."

Individuals are referred to Boost in a process similar to the one utilized for special education. Each team meets at least one time per week, and individual student issues are discussed at this time, as well as informally at other points throughout the week. Teachers report that at meetings they: share information about students, such as behavior which they find problematic in their classroom; check to see if a student's behavior is replicated in other classrooms; and discuss appropriate strategies for dealing with a student's misbehavior. Behavioral interventions are utilized and documented by the team. Next, as described by one team member, "we meet with the Boost people and see if that student fits in, and then we met with the parent and see if the parent feels that the child will benefit; if the parents are in agreement, we go to Boost." Some teachers reported that the parents were involved before the referral to Boost, while others indicated that parent involvement usually occurred after a referral was made. "We have a step in the middle that we try to go through before a recommendation to Boost, and that is to actually get the parents in to get them involved and talk to them... and try to come up with a plan." 
During the interviews, teachers demonstrated a wide range of variability in their understanding of the type of student who would most likely benefit from the Boost program: "Boost is to give them a boost. I don't think it is for really difficult kids" and "For the most severely impaired behavior problems we have a program called Boost," "If there is a difficulty between your academic ability and what you can do, then you are put in special ed. I look at Boost as more as a place where the behavior kids go." "If they are not severely handicapped and they can handle the material, they are in special education."

Teachers generally did not describe "special education" programs for students with behavioral difficulties. A few teachers described how students with severe behavioral issues are assigned full time aides, but for the most part special education was viewed as a means of addressing poor academic performance. Teachers also demonstrated a great degree of variability in understanding the school- based programs currently in place for students with behavioral issues. All teachers interviewed described Boost. A few teachers described another "behavior room," whereas other teachers denied that such a room exists.

Teachers also reported that students with extensive behavioral needs might be referred to out-of-district placements. Specifically, one teacher reported that students who experience significant behavioral difficulties in the eighth grade might be referred to an alternative program at the high school or a vocational program. No teachers interviewed mentioned the possibility of an out-of-district therapeutic placement.

In addition to formal educational programs, the school where the interviews were conducted also has a unique program designed to address the needs of "at risk" adolescents by participating in an intensive outdoor experience:

It is an outward bound, type of activities thing. ... They have a goal, and it is tied into the academics. It is tied into the plan, academically, they have to do well and they have to get along socially, emotionally. I think it is a great program. 
Students are identified by teacher to participate in the program. Teachers report that they look for students who have potential but are not doing well in school for any number of reasons. The students are selected for participation, and then they train for a number of months leading up to the trip. Students then are taken on a wilderness expedition where they do various outdoor activities, such as canoeing, camping, hiking, and ice fishing. Two trips run each spring and fall, one for each gender. This program is viewed as being ancillary to a students' "normal" school program and is not tied into special education or the Boost program in any way.

In addition to "formal" educational programs, the teachers reported that they often utilize other resources within the school to address the various behavioral needs of students. Teachers mentioned the guidance counselors as the resource often accessed when they had a question or concern about a student. Teachers varied in their usage of guidance "My first place to go is to the guidance counselor. I like to go to that person because they have a connection to the home and they know the past history of that person or whatever." Teachers demonstrated a common theme of using guidance when they were concerned about the emotional well-being of their students. For example, one teacher relayed that they would utilize guidance when the following scenario was demonstrated: "I had a girl here a couple of years ago... where every time she came in here she was crying." Specifically, teachers shared that they would approach the guidance department when:

(there are) changes in behavior. I don't mean flipping out... kids becoming sullen, or grades suddenly dropping, or looks don't matter or comments about this doesn't matter anyway; something different from what we have seen previously; if we know somebody is having a problem, the home situation, we are bound by law to report that to higher authorities; sexual, and physical abuse; drug and alcohol use; we think there is some sort of stressful event going on in their life that we think might be responsible for their abnormal behavior. 
In addition, one team reported that they use the guidance counselor in the pre-referral process. Specifically, this team meets with the parents, teachers, and guidance counselor, and comes up with a plan before the student is referred to special education. Only one teacher interviewed reported using the guidance counselor in this capacity.

Teachers commonly reported that the guidance counselors were viewed as professionals who were able to deal with students' psychological issues which may be negatively impacting their behavior in school. Referrals to guidance appeared to exist independently of the student's academic performance, meaning that teachers might refer a student to guidance even if a student's academic achievement was satisfactory. According to teachers, each guidance counselor demonstrates a unique approach to dealing with students' issues. Some guidance counselors utilize formalized groups around content areas, such as divorce or dealing with parents who suffer from alcoholism, whereas others have an informal approach where they meet with students individually on a touch and go basis. Consequently, teachers report various results to referring a student to guidance.

One difficulty teachers repeatedly stated about utilizing guidance services is that: "guidance is overburdened with students right now, they can't get to all of the students." Another teacher stated "1100 divided by three, almost four hundred students and one guidance counselor, that is ridiculous. One doctor to four hundred patients in a hospital?" Teachers report that the high student/counselor ratio precludes counselors' efficacy to a certain extent because "(the guidance counselors) are lucky to know (the students') names, much less talk to every one of them;" ..." in reality there have been crises that have evolved and guidance hasn't seen that child until two days later." Throughout all of the interviews, teachers were supportive of the role and intent of guidance counselors, and understanding of how counselors were easily overwhelmed with the demands of meeting the needs of the 400 students on their caseload: "It's an issue, it is not because the guidance counselors don't care, it is because they have so many kids they are trying to deal 
with." As a result of the school's size, therefore, teachers feel as if guidance counselors are unable to completely meet the varied and unique demands of their students, simply due to their lack of accessibility and availability.

When reflecting upon their referral practices to the guidance counselors, teachers shared that they referred girls to guidance more often than boys: "I think I refer more girls. I haven't thought about it, but I think I refer more girls than boys. As I remember, a lot more girls than boys." Teachers also reported that female students appeared to want to go to the guidance counselors for emotional support, and would even sometimes walk out of class or disobey the teacher's directions in order to see their guidance counselors.

In addition to guidance counselors, teachers reported utilizing other professionals within the schools as resources when dealing with student's behavioral issues. Teachers indicated that they would turn to the principal, drug and alcohol counselor, and school psychologist. Principals were viewed as integral participants in the management of student issues, particularly around discipline. "It would go to the administration of it was really serious." (if) "it is something major, then I go to the Principal." "The Principal is also involved on any behavioral incident that happens on the bus." In addition, principals were directly involved when students were involved in physical altercations. The school drug and alcohol counselor was reported to serve in a consultative capacity, working with teachers around student issues and serving to provide information in the pre-referral practice: "there is a drug and alcohol counselor I have consulted with a few times this year." The school psychologist was also reported to serve in a consultative capacity, "I rely on the school psychologist a lot...we used to sit down with him to help us put a program together." Only two of the sixteen teachers interviewed reported utilizing the services of the school psychologist, indicating that his role and function may not be well understood within the school, or his services may be primarily utilized for testing: " I don't know exactly what the school psychologist does. I know that during a Pupil Evaluation 
Team the school psychologist has tested those kids and tried to come up with tactics for us to use in the classroom to help with that child."

Throughout the interviews, teachers often reflected that the size of the school had tremendous implications for the structure and intent of school programs. For example: "This place is so big. They've gone and made us a huge school, 1100 middle school students out here in rural Maine" and "It is too big of a place. Kids slip through the cracks here because there are just way too many kids," "it is a big school here and you go through the year and you see some kid in the hallway and you think I have no idea who that is... You just look at them and say, I hope they found something here this year."

In order to address the issue of school size, two organizational innovations were developed. One was an Advisor/Advisee program instituted five years ago. The second change was the formation of teacher teams to provide all academics to groups of students.

The Advisor/Advisee (AA) program was described as a school wide program designed to facilitate the development of relationships between teachers and school staff. One teacher described the AA program as "a contact program so my group has thirteen kids and those thirteen kids could come talk to me if they had a problem." Individual teachers are assigned small groups of students which they meet with during an Advisor/Advisee period. The intent of the program is to facilitate the development of positive relationship between students and staff. In addition, the student's advisor is seen as a resource to assist the student in addressing school-based difficulties they may be experiencing. One teacher reported that the advisor advisee program is an attempt to address the difficulties inherent in being a large middle school. Advisor/Advisee is a program designed to prevent students from falling through the cracks. Some teachers questioned the efficacy of the AA program because:

I think some teachers are uncomfortable with it. They are uncomfortable talking with students about sensitive issues. Teachers don't feel prepared to handle what some advisees might tell them. Some people feel that they are in school to teach and the advisee program does not fall under that. 
Teachers commonly shared the following sentiment about the AA program: "It needs some work, but I think the whole program can work."

The second organizational innovation utilized to respond to size is the use of teams. The school is currently organized to provide sixth and seventh grade students with three teachers who provide all of their academic subjects. "Now they try to break us down into friendly little clans with three teachers in each, and they are trying to make a small school atmosphere." It is hoped that through formulating small teams, teachers will have a greater degree of contact with students, which will result in teachers being more attuned to students' behavioral, emotional, and academic needs. One teacher reported that having smaller teams is beneficial because "I think that being close enough to them, to observe those things is probably the key thing. If you just saw them for 45 minutes a day, it is difficult to observe those things. See them for a couple of hours, $2 / 12$ hours per day, it becomes a lot more obvious." In addition, it is felt that students will feel more secure with teachers to whom they have a higher degree of exposure, which in turn facilitates the development of teacher/student relationships: "The fact that we have moved to three team teachers, the kids having a problem might utilize the fact that they can use one of their teachers, we like to think that, I can see how in some situations they might not want to." In addition to structuring smaller teams, in the 1995-1996 school year the sixth graders were segregated to their own wing of the building to attempt to foster a sense of community among them.

Throughout the interview teachers repeatedly asserted that the physical size of the school, and the number of students attending the school had a negative impact on the school environment. According to one teacher, "we are going to segregate the sixth graders, none of that helps. It just doesn't work, it is too big of a place." The size of the school, the number of teachers, and the number of other school personnel (i.e., administrators, guidance counselors, counselors) may account for the high degree of variability in teachers' responses. When questioned, all teachers responded that they 
would refer students to guidance for emotional/behavioral concerns, and to the principal for serious behavioral and discipline issues. Apart from those commonalities, teachers basically demonstrated idiosyncratic response styles. Various professionals were utilized in disparate manners. Some teachers never utilized professionals other than guidance counselors, other teachers consulted with school professionals, while still others utilized some school professionals and not others. This high degree of variability demonstrates that the teaches and teams may utilize a variety of individuals when addressing students' needs, resulting in the provision of disparate services.

\section{Referring Students for Behavioral Issues: General Practices}

Throughout the interviews, teachers reported using a similar process across teams when referring students to the Boost program. All teachers indicated that when they experience difficulty with a students' behaviors, they work with the student in their classroom to identify and address "problem" behaviors. A number of teachers reported that in this process, they generally talk individually with the student to find out why the behavior is occurring: "We just try to pull them aside and say something to them."

When the student's behavior continues to be of concern, the student and his/her behavioral needs are discussed at a team-wide level. When sharing information about students, however, teachers indicated that teams utilize different techniques to communicate important information about student performance. All teachers indicated that the team meeting is a crucial forim for presenting concerns in a weekly meeting. Some teams utilized formalized procedures. "We meet twice a week as a team and we each bring any notes we have about problems we've had with kids, whether they're emotional, behavioral, or academic, and we talk about them and see if there are any common strands." At the team meeting, teachers share information about how the student presents in their classroom and commonalities across classrooms and between teachers are noted. Some teachers reported that they attempt to come up with a team- wide behavior 
plan to ensure that the students' behaviors are addressed in a systematic and consistent manner.

Other teams indicated that in addition to team meetings, a number of teachers reported that they find it highly effective to share information informally "probably our group gets more done informally. We have been working together for years, so we get a lot accomplished that way... " Teachers reportedly talked to each other in the hallways, between classes, and during other free periods on an as-needed basis.

Once an issue is identified with a student, the teams attempt to address the concern in varying ways. One team reported that they may utilize a wide number of interventions including: talking with the student individually; calling the parent; talking to the students' exploratory teachers (physical education, art, industrial arts, consumer science teachers); or having the school psychologist observe. One teacher shared that a behavioral contract would be set up between the team and the student before the student was referred. Another team reported that they have they involve the parent in the decision- making process, and that they hold a meeting with the guidance counselor and parent where the team identifies a behavior program to implement. It is clear, therefore, that once a difficulty is identified, teams utilize different means of addressing their concerns, and may involve different school personnel in the process.

All teachers reported that in the referral process, the team then implements team wide behavioral interventions, and the students' reaction are documented. "We are supposed to try a lot of things before we send them to Boost, and we have generally tried some." Teachers generally recognize the importance of addressing the students' behaviors within their current environment before referring to alternative programs for assistance.

Some students do not benefit from the implementation of a team-wide behavior plan, which then results in the team contemplating whether an alternative placement will best suit the needs of the student. In this decision-making process, the teachers, parents, and administrators discuss school programs which might be more appropriate to meet the 
needs of the students." We meet with the parent and see if the parent feels that the child will benefit. If the parents are in agreement, we go to Boost. If the Boost program is not an option, then we have quite a few meetings." One teacher also indicated that input from an administrator around discipline issues may facilitate the referral of a student to the Boost program. "Maybe (the administrator) has dealt with this kid enough, the team teachers have dealt with this kid enough, and ... eventually we all just say, enough is enough. See if we can get him into the Boost program."

\section{Variation in the Referral Practice}

Teachers reported that the number of referrals to the behavior program seemed to vary from team to team, depending upon each one's unique standards. Teams with higher tolerance levels for behaviors generally did not refer students to the Boost program as often as teams with lower tolerance levels:

The kids in one room may be placed in the Boost room or given a behavior label, they may not be as severe as the students in another clan because the teachers in that clan have a higher tolerance.

A student's placement in the Boost program may also be dependent upon how motivated the team is to remove him/her from their classrooms:

a group of teachers get together and say, "We have a problem with this kid and we need to do something about him." They talk to the administration, the administration has a PET, and the next thing you know, the kid is in the Boost room, good, bad or indifferent. Whether they belong there or not. I think that there are other kids who should go in there first.

In addition, one team may be more adept at addressing behavioral issues through their behavior management practices and may contain "low end" behavioral issues more effectively. Consequently, a student's placement in the Boost program is directly dependent upon how their team perceives their behavioral difficulties, if the team has a high tolerance or low tolerance for that behavior, how the team manages that behavior, and how motivated the team is to remove the student from their classrooms. This practice 
results in a significant amount of variability in who gets services and why services are warranted.

In addition to team-wide variability, individual teachers were felt to have a wide range of variance in determining which behaviors were appropriate. One teacher stated, "Unfortunately, I feel that the teachers with the lower tolerance are defining the behavior more than the teachers with the higher tolerance." Teachers with lower tolerance levels, therefore, refer more studénts to their teams and place a higher emphasis on having the students receive services. It appears as if difficulties are perceived as existing within the student, not the teacher. Throughout the interviews, all teachers noted how the teams and the administration responded to the low tolerance level of the teacher through invoking the referral process. No mention was made of intervention from the administration or team leaders designed to improve teachers' classroom management skills and thus increase their ability to manage disruptive behavior. This focus on teachers' diverse tolerance levels results in some teachers and some teams referring more students, while other teams are able to address the behaviors within the teams.

Teachers readily noted that the school's current referral procedure is a general guideline and not always followed in practice. In some cases, they reported feeling as if students were quickly placed into the Boost program in response to outside pressure from the parents, or in instances where the administration felt it best to expedite the process. One teacher shared a story which caused her to be confused and concerned regarding the referral process:

I had a student at the first of the year who was placed in Boost for a week. I was told, well, sometimes we need to shortcut the system and then he was in Boost for three days and then he was back in the classroom. I questioned that, how come he was ready to go... He had so many behaviors that they were willing to shortcut the system.

The placement process was also reported to be dependent upon the availability of open "slots" in the behavior program. "(In the behavior program) the enrollment is a vacancy 
kind of thing." One teacher reported that "in this particular year, we have a couple of girls, that could be sent to the Boost room, but by the time we learned of their behaviors, the Boost room was full."

Teachers also reported a degree of confusion regarding the criteria for entrance into the Boost program: "I am not totally sure what the qualifications are to get in there" and "I am sure that there (are criteria)." I am not exactly sure what it is... I don't think it is articulated to us very clearly. Just sort of, if you are having problems with a kid in a class and they are continuous problems then you can call Boost." One teacher reported that teachers were provided with a program description at the beginning of the year regarding the structure and intent of the Boost program. It is possible that their level of confusion results from variability in who is placed in Boost, why that student is placed in Boost, and the procedure for placing that student in the program.

The teachers also shared some confusion over when students should be referred to Boost, a non-special education behavior program, and when they should be referred to special education for having a behavior impairment:

I am not sure that I have a clear understanding of which type of kid goes into which. I think that is my problem. If there is a problem with kid $\mathrm{X}$, does he go in the behavior room or the Boost room. I don't know what differentiates the two."

Another teacher reported that:

I tried to find out what the criteria here was for special ed and I couldn't find out. They told me that behavior was not criteria for special ed.

Some teachers were generally confused about the difference between the Boost program and special education, and could not clearly identify when a student would be referred to one and not the other. Other teachers conceded that they felt that they knew the various school programs well, and were adept at referring students to appropriate places. "We have students with behavior problems, but if we don't feel like they will benefit in that 
situation, we don't even refer them. It would be using that resource to no avail, unnecessarily."

A consistent decision-making process when referring and placing a student in the Boost program or special education for behavioral concerns was not apparent through the 16 interviews conducted. Specifically, teachers reported:

I don't think that we have a consistent policy, at least that I am aware of, and I've been here a while.

I think there is just too much variation there.

I see us jumping around, depending upon who is involved and how quickly they want to get rid of the problem.

I think it is fairly subjective. I think there is an attempt by the people involved... to make it objective.

It could be that it is rather haphazard. We are rather subjective about it...

Consequently, some teachers demonstrate confusion as to the proper course of action when a student is experiencing difficulties. Other teachers reported feeling that the system's reaction to the needs of a particular student was essentially idiosyncratic, depending upon the needs of the students, the tolerance level of the team, the parents' desires, the needs of the administrators, and program availability. One teacher demonstrated a clear frustration with the lack of a definite and consistent referral practice, from his point of view:

We had another kid here who got suspended multiple times in the beginning of the year who never got into the behavior rooms... He went right from becoming suspended eight times in the first three months of school to being here half a day with a tutor.... that's not the way it ought to happen. He never even had the chance for the behavior room or the Boost room, he never even had that shot.

The same teacher then offered some insight into how the current referral practice for behavioral issues could be improved:

We ought to have a bunch of steps that we follow, and that if we try a step and it has failed, then let's try a different step. And they are not so much as sequential as much as a list of here are the different things we can do... I don't see us doing this. 
Consequently, teachers responses reflect a significant degree of confusion regarding the current referral practices to Boost and special ed for behavioral disorders.

\section{"Typical" Characteristics of Students with Behavior Disorders}

When asked to describe common characteristics of students referred to special education or the Boost program for behavioral disorders, teachers provided responses that were classified into six general categories: talking out; peer difficulties; aggressive behavior; disobeying rules; attention seeking behavior; passivity which negatively impacts academic performance; poor emotional management skills; and attentional/ impulsivity issues. One teacher generally described students with behavioral issues as "kids... who don't fit the mold... Most kids figure out that if a teacher asks for $\mathrm{x}$, I should give them $\mathrm{x}$ and then we'll work through this. But in some situations, if they expect $\mathrm{x}$ and get $\mathrm{y}$, they don't work to change that."

\section{Attention Seeking Behavior}

As a broad category of behavior, teachers indicated that students with behavioral needs generally demonstrate behaviors that result in attention from others. Specifically, students with behavioral needs act in the following ways: "Do whatever they can to make them say, hey, look at me," "They just really want the attention. They want my attention, they want the other kid's attention" and "They have clearly learned deviant ways of getting attention." The responses of the teachers suggest that most students gain attention by not following the rules of the school and society, usually in an overt way. Teachers report being most bothered by behaviors which cause the student to come into conflict with the rules, or other students. As a result, generally, students with behavioral issues may be seen as gaining attention through their inability to appropriately follow the normal course of behavior expected by students within school settings. As teachers report, students with attentional issues may have a lack of positive social and academic skills, which result in 
difficulties gaining attention from others for appropriate behaviors. Instead, students' need for attention may be satisfied through engaging in deviant behavior which results in the receipt of negative attention from school staff and peers.

Disobeying Rules

Teachers indicated that students likely to be referred to special education for having a behavioral impairment generally experience difficulty following the rules of the school. Specifically, teachers indicated that students with behavioral issues tend to experience difficulty obeying the rules on a school-wide level. These students are reportedly:
Always late for class
Wandering the hallways
Truant

Teachers also shared that students with behavioral issues generally do not follow the rules of the classroom and engage in "misbehavior to the point where they are manageable in the classroom with the rest of the kids" Specifically, these students:

Get thrown out of class a lot

Don't sit down

Disruptive

Always fooling around

Within the classroom, therefore, teachers again tended to report behaviors that they found to be disruptive. A common theme elucidated was students with behavioral issues challenge the teacher's classroom management. Within this context, it was reported that students break the rules in an overt manner that forces the student's behavior to the attention of the teacher. By being disruptive, getting thrown out of class, and so on, the students require the direct attention of the teacher in order to be brought under control. In no instances did teachers state that students broke the rules of the classroom by inaction. 
In addition, teachers reported that students with behavioral needs may demonstrate asocial behaviors such as:

Doing things that are illegal

Asocial type behavior

Lack of decorum, control, rules of order

A few have disturbed images of what appropriate sexual activity is

These statements suggest that teachers feel that students with behavioral needs have not internalized the "rules" of the school or society to a degree where they are able to comply. These types of students may be of concern because their behaviors do not correspond with the norm for how students are expected to act. These students deviate in terms of their overt misbehavior which challenge the authority of the school or the teacher in some way. Teachers were generally not concerned with deviant behavior which did not challenge their authority and did not disrupt the learning process for the other students.

\section{Attentional/Impulsivity Issues}

In addition to demonstrating impulsivity in their decision making strategies, teachers reported that students with behavioral issues generally demonstrate a high level of energy in the classroom. For example, teachers reported that they are: "Wound up all of the time," "They are just flying," "They want to go, go, go, go, go." In addition to demonstrating a high energy level, teachers reported that these students generally demonstrate a "Short attention span," experience "difficulty paying attention," and "Can't sit still for any amount of time." Many of the students described by teachers in this category may fit the classification of students with Attention Deficit Hyperactivity Disorder. Again, students of concern to teachers may demonstrate poor emotional management skills, and difficulty focusing their attention on the material at hand. It is possible that teachers are highly concerned with these students because they are disruptive within the context of their classrooms. Students who can not focus on the material presented, and who are on the "go" all of the time, may present difficulties for teachers in 
terms of classroom management. In addition, these types of students may be disruptive simply due to their need to physically explore the environment as the teacher is attempting to present a lesson. These students also may be a challenge to instruct due to their difficulties attending to academic material.

Aggressive Behavior

Teachers demonstrated a consensus that students with behavioral issues demonstrate a wide range of aggressive behaviors. Specifically, teachers provided the common characteristics of students referred for special education services under the BD classification:

Pushy sort of aggressive behavior where they are on the edge of problems a lot of the time

Often angry

Overtly aggressive

Propensity for violence

Students of concern tend to demonstrate general levels of aggression within the classroom and school environment. Teachers also agreed that students likely to be referred also demonstrated aggressive behaviors towards themselves or others in the classroom:

Aggressive to either the students, myself, or harmful to themselves

Aggressive with their peers

Touching people inappropriately

A lot of hitting kids in class

Can't keep their hands to themselves

Starting fights

In addition, students likely to be referred were also reported to demonstrate poor anger management skills:

Throwing chairs

Tantrums

Destructive

These responses suggest that teachers are highly concerned with aggressive behavior within their classrooms. It is likely that teachers are highly concerned with aggressive 
behavior because it is highly disruptive. In addition, teachers may be concerned about their safety, the safety of the other students in the classroom, and the safety of the student experiencing the difficulty. It is this concern, and the sheer disruptiveness of the student, which may motivate the teacher to refer the student out of their classroom. In terms of motivation, teachers may be likely to focus energy on a student which they find threatening. As a result, teachers may be highly likely to refer students for aggressive type behaviors because they may directly benefit by having the student removed from their classroom, insuring the safety of themselves and the students in their classrooms.

\section{Talking Out}

Throughout the 16 interviews teachers demonstrated a great deal of concordance in their feeling that students with behavioral issues tended to demonstrate a significant number of talking out behaviors. Teachers replies indicated that students with behavioral issues tended to demonstrate the following behaviors:

They have to talk out in class

Always talking

Ones who can't be quiet

Speaking up constantly

Interrupting

Mouthy to an extreme degree

Screaming

Yelling and screaming at the other students

Disruptive

As teachers indicated, they generally find this type of behavior to be disruptive within the context of their classrooms. Some teachers indicated that this speaking out tends to have aggressive overtones, such as yelling and screaming at the other students. This response, along with the mouthy-to-an-extreme-degree response, suggests that students with behavioral issues generally do not follow the "rules" of the classroom, whether those rules are implicit or explicit. 


\section{Peer/Interpersonal Difficulties}

Teachers also indicated that students with behavioral issues generally tend to experience significant interpersonal difficulties. Teachers provided the following characteristics of students with behavioral issues:

Don't have social skills

Someone who can't get along with anybody

Tend to have a real difficult time, mostly with relationships with other kids or the teachers

Tend to have a difficult time in groups

Not able to get along with other kids

Inability to make friends and interact with others

These responses suggest that $\mathrm{BD}$ students have poorly developed social skills, which render them unable to effectively participate in the social aspect of classroom activities. Teachers indicated that inappropriate social skills could exist both independently and concurrently with social isolation from peers. When specifying the nature of the students' social deficits, teachers offered differing opinions on the "typical" nature of students with behavioral issues. One teacher remarked generally about BD kids:

They are disaffected where they don't belong to much. You don't see them attached to many groups or teams and those types of things, they are usually loner type kids.

This response indicates that to a certain degree, students with behavioral issues may demonstrate introverted behavior and withdraw from "typical" social interactions of adolescents. A number of teachers indicated that students with behavioral issues generally tend to demonstrate social behaviors where they antagonize other students and teachers. Teacher responses indicated that "typical" students with behavior disorders:

Make fun of other kids

Put other kids down

Bother other kids to such a degree that it draws the other kids into it General name calling, belittling, harassing type of behavior

Complete verbal harassment to teachers, to the students

Doesn't show respect for authority or their peers 
Again, these responses suggest that the student is demonstrating aggressive behavior towards their peers. It is possible that teachers see students demonstrating a range of maladaptive social behaviors. Generally, students referred for BD services may demonstrate social behavior where they demonstrate a high level of conflict with their peers. When asked to conceptualize students with behavioral issues, some teachers report that they are most concerned with overt social disagreements between students, possibly because it is disruptive within the context of the classroom. Some teachers also find students who demonstrate withdrawn social behavior to be at risk, though fewer teachers reported being concerned with social isolation than aggressive types of behaviors.

\section{Poor Emotional Management Skills}

In addition to demonstrating poor interpersonal management skills, students with behavioral issues tend to demonstrate poor intrapersonal management abilities. Teachers stated that students with behavioral needs generally demonstrate difficulties managing their emotions in an adaptive manner. As one teacher stated, students with behavioral needs, "... don't know how to cope." When faced with stressors, or decisions, they demonstrate an inability to manage their emotions in a way that produces satisfactory results. Teachers demonstrated a consensus on the belief that students demonstrate poor decision-making abilities:

Don't know how to make good decisions and good choices

Don't know how to weigh things and see what the consequences are going to be

Don't care about consequences

Little self control, lack of control

Nobody has ever taught them any self discipline

From these responses, it is clear that students with behavioral needs demonstrate difficulty understanding the outcomes of their decisions, and responding accordingly. It is also possible that students with behavioral issues tend to demonstrate an impulsive response style, where decisions are made rapidly without a full understanding of long term 
outcomes. Teachers reported that students "Just lose control," are "Out of control," and "Act irrationally and spontaneously."

In addition, teachers also reported that once a misbehavior or maladaptive behavior occurs, students: "Tend not to be able to take responsibility for their behaviors" and are "Not able to own problems." As a result, students respond quickly to difficulties, and are then unable to see the part they played in determining the outcome.

\section{Passivity which Negatively Impacts Academic Performance}

Teachers elucidated one category of behavior that deviates somewhat from the other areas of concern outlined for students with behavioral issues. For all other categories, teachers experienced concern about a student because of the maladaptive behavior they were demonstrating within the school setting. Teachers, however, also reported that they experience concern with a student's inactivity as it pertains to the completion of academic assignments. Teachers shared that some students with behavioral issues demonstrate the following behaviors:

Doing absolutely nothing, bump on a log, do you have a pulse kind of deal There, but not there

Doesn't do anything, just sits in the classroom.

The ones who lay back in their chair

Apathetic

Lethargic

Didn't do their homework, wouldn't bring their books to class, saw no reason to perform.

Won't do work

Not trying

Not learning

Generally, teachers were concerned with a lack of energy as it had a negative impact on the student's learning. Teachers did not indicate that students who are withdrawn or passive but completing their work were of concern within classroom settings. 


\section{Summary}

Through teachers' responses, it is clear that students with behavior disorders tend to be disruptive and demonstrate deviant behavior that does not correspond with the demands of the school setting. Most areas of concern outlined by teachers focus on students' misbehavior which cause them to directly come into conflict with the "rules" of the school setting. Teachers may focus upon these behaviors because they are most disruptive within a classroom setting, and may negatively impact the classroom environment. Teachers, therefore, report that classroom control is an essential component of structuring a positive learning environment. Students with behavior disorders tend to disrupt their classroom control and subsequently have a negative impact on the learning of other students. In addition, teachers only elucidated one area of concern regarding a students' inactivity within the school setting. Based upon the teachers interviewed, teachers are only concerned with inactivity as it negatively impacts academic performance. During the interviews, teachers reported that they were concerned with other types of behavior demonstrated by students (i.e., a student who is: crying; suffering the effects of an alcoholic parent; dealing with divorce). Concerns regarding these behaviors, however, are not addressed within the context of the formal special education referral process. Instead, informal mechanisms appear to be utilized by teachers in having these behaviors addressed.

\section{Benefits of Referring}

When questioned, teachers articulated a number of areas in which they benefit when they refer a student to special education or Boost for having a behavior disorder. Through initiating a referral within their teams, teachers noted that they benefited by improving their classroom environment, the student referred benefited by receiving additional services, and the students in the class with the student referred benefited by having the disruptive student removed. Teachers generally felt that referring a student to 
special education had positive outcomes and improved their effectiveness within the classroom.

When questioned, teachers indicated that students with behavior disorders demand a significant amount of time and energy. The benefit that most teachers articulated about referring a student to special education is "Getting student out of classroom." As one teacher stated: "I think that the biggest benefit that we get is that we don't have to deal with the kid. Kind of crass to say, but usually by the time we make a referral and the kid is put in a program you are like, phew, I don't have to deal with that." Teachers reported that they feel drained by addressing the needs of the student within their classroom, possibly due to the student's disruptive behavior: "It is an enormous load off of your shoulders to not have to deal with one of these kids day in and day out;" "(you can) go home at night and not be exhausted." As one teacher simply stated, "You are given respite."

Some teachers recognized that in many cases, the referral primarily benefits the teacher by decreasing their stress level: "It doesn't help the kid necessarily... it might help the situation." One teacher stated that the student may benefit from being removed from an environment that the teacher finds stressful: "the benefit that most people see is to get the kid out of their room, and that is unfortunate. I suppose if it gets to the point where you are going to kill the kid, then it is a benefit for them too." Thus, the primary benefit stated by teachers in the referral practice was the benefit they incurred as classroom teachers from having a difficult student removed.

Teachers also indicated that a special education referral could allow the teacher to obtain additional resources: "I think it does help you in order to get some outside resources. Just another outlet for you too, you can talk to them and get help;" "(teachers) gain when they refer a student if they get some help from the special ed department;" "Another person looking out." Thus, teachers felt that referring a student benefited them when they were able to gain assistance from special education teachers. It is possible that 
having another teacher involved with the student decreased the referring teachers' stress level. Teachers' responses indicate a desire to work more effectively with the disruptive student, noting that additional resources are often essential components of this process.

Teachers reported that the rest of the class benefits by referring a student with behavioral issues to special education. Implicit in this belief is the notion that students with behavioral issues are disruptive within the context of the classroom. "There are some of these kids, the minute you try to teach the rest of the class anything, they are going to disturb your whole class." Teachers commonly voiced the opinion that the disruptive behavior of one student often negatively impacts the education of the other students in the classroom: "The other kids deserve an education too and that one problem child doesn't have the right to take that education away. And often that is what we are seeing now." By having students referred out of the classroom, a significant source of disruption is removed, which allows teachers to focus more energy on the remaining students: "When teachers are not focusing their energy on the disruptive student, the rest of the students benefit by having more time and attention;" "It gives the teacher... time to deal with other kids... some time to work with kids without that interruption." Students with behavioral issues, therefore, are seen as detracting from the educational process due to their deviant behavior. Again, it appears as if the common characteristic of these students is that they engage in overtly maladaptive behaviors which challenge the order of the classroom.

In one interview, a teacher indicated that one benefit of referring a student to special education is that (the student referred out) "gets their work done." Based upon the responses presented, it is clear that the needs of the teacher (i.e., how disruptive they find the student to be, and how much energy they demand) often drive the referral. The positive results elucidated generally benefit the teacher and the rest of the students, with a minimal focus on the needs of the student who is placed in special education. This pattern suggests that referral practices are highly teacher and team dependent: focusing on the threshold of each individual teacher or team instead of following some type of 
pre-established behavior criteria for students. Again, the variability in teachers' and teams' thresholds for disruptive behaviors leads to inconsistency regarding the level of behavior demonstrated by students referred to special education for a behavior disorder.

\section{Students Who Fall Through the Cracks}

Throughout the interview, when asked to describe the types of students who fall through the cracks of the current educational system, teachers demonstrated a high degree of concordance in their responses. Teachers generally agreed that withdrawn and quiet students tend to fall through the cracks and not have their issues addressed: "(students are) misread as being fine but quiet and not needing a lot... They're overlooked."

Teachers recognized that withdrawal and isolation may signal deeper psychological issues in students: "Sometimes they are just looked upon as lazy or unmotivated where it could be something more, but I think a lot of times it goes undetected or un-pursued." Within the current school structure, however, it appears that the needs of the quiet student are not viewed as seriously as the needs of students who act out their difficulties in other ways: " I think (the kids overlooked are the ones) who might be having some trouble but they are putting it inward... they might be having some of the same issues as the other kids who are telling you to take a leap, but they are directing their stuff inward and so you see them as shy or maybe, you know, you overlook them."

In explaining why these students may be overlooked, one teacher explained, "they just sit there and don't give you any grief... not doing anything enough to have a red flag come up and just suffering." Another teacher explained that behaviors which are considered to be "problems" by teachers are first given attention, on the other hand "the kids where you can tell that there is some stuff going on, but it is directed inward, and those are the kids who are easy to get lost in the shuffle because they are not overtly causing a problem." One teacher described how she is much more likely to react to students who "are demanding of (her attention), who are an immediate threat." Teachers, 
therefore, were able to recognize that they allocate a disproportionate amount of attention to students who are disruptive within the classroom:

In actuality, it is probably the behavioral kids who get the attention because they are lashing out all of the time and they are creating the problem. They are not keeping it inside. They are saying, "I am not a happy camper and I am going to tell you about it. You're going to have to hear about it, and you're going to be an unhappy camper when I get done." This is the way it is until they can get that problem solved. The kid who is taught and has learned that you are quiet and that you behave yourself, and just suffers and suffers, and suffers... Gets missed too often, way too often.

Teachers, therefore, appear to first direct their attention at the students who are a threat or disruptive within the classroom context. It is important to note that the teacher clearly defined the disruptive students as being "behavioral," thereby suggesting that withdrawn students are not conceptualized as demonstrating behavior disorders within school settings.

Throughout the interviews, however, teachers demonstrated concern with current practices. When discussing withdrawn students, teachers reported that: "Their continual isolation is affecting them. They are getting alienated, too, but because it is not lit up with fireworks and stuff, you don't necessarily catch it until something happens where one day they do explode." One teacher recognized that externalizing students typically receive attention and referrals to special education, a practice that may not meet the needs of students who manifest their difficulties in disparate ways: "You miss a lot of the kids because you are dealing with so many other problems. You will miss that kid who is withdrawn and could be abused or something... we often just don't pick up on it, it's not that we don't care... but one standard is applied." Consequently, the behavioral needs of quiet students are not addressed in the same manner as the behavioral needs of externalizing students.

Teachers also identified that by focusing attention on the students who are disruptive, the academic needs of quieter students may not be addressed: 
Once again, I am a great example of a guy who the behavior problems are the first people I jump on and I know them well. But the kid who is sitting over in the corner and is very quiet, I can miss them. I had a couple years ago, three behavior kids in the same class... My beef was in the back of the room there was this very nice quiet kid, who wasn't the brightest bulb in the circuit, but was a nice kid and who would do anything you tell him to do as long as he could, but often he couldn't. He slipped through the cracks in my classroom because by the end of the semester he knew very little because I was not able to get back there because I had to sit on those three clowns.

Thus, teachers identified that students who are quiet and withdrawn may not have their psychological issues identified in the same manner as externalizing students, and their academic needs may be overlooked.

Inherent in teachers' responses is the belief that students demonstrating internalizing behaviors are not appropriate to refer to special education or the Boost program. Though this practice was not explicitly stated within the teachers' responses, it is clear that teachers felt that students demonstrating withdrawn and isolated behaviors were more appropriately served by the guidance counselors. The special education referral process was viewed as a means of addressing students demonstrating externalizing behaviors. Students demonstrating internalizing behaviors, therefore, are perceived as "falling through the cracks" due to the lack of a formal program or process within the current school structure. Consequently, teachers may utilize an idiosyncratic approach in addressing the wide range or internalizing behaviors demonstrated, and the current system may not have the resources to deal with a large number of students presenting with "mental health" needs.

In explaining how and why quieter students are overlooked, teachers provided answers that correspond with the economic theory of teacher resources (Shinn et al., 1987): "The squeaky wheel gets the grease." One teacher explained how disruptive students affect the climate of their classroom, and their ability to present academic material "You want to get something done and they prevent you from getting something done and they know it. I know how I can get my needs met. I've just got to cause enough 
commotion that my needs are going to be met, and my needs are attention, maybe, and I will get my needs met anyway I can. We do give it to them." By causing a "commotion," therefore, students are deserving of teacher attention. Because teachers have a limited amount of time and energy, quieter students tend to get overlooked: "There are a few who are really quiet in class, don't do anything, and you know that there is stuff going on at home. (Their needs aren't met) because they don't interrupt class, and they don't hurt the learning for the other kids, they just don't get the attention that probably they should. We just don't have the time. I think a lot of teachers, with me included, if they don't bother us, let them sit and do whatever they want."

Through the discussion of current practice, teachers convey two main themes. First, teachers admit that they do not feel as if they are adequately addressing the needs of students demonstrating internalizing behaviors within their classrooms. Teachers generally use the word "behavior problem" and "behavior disorder" to refer to students who are demonstrating externalizing behaviors. Teachers tend to view special education as a modality which may provide interventions designed for and appropriate to the needs of students with externalizing behaviors. Second, teachers also report that they prefer to remove students demonstrating externalizing behaviors so that they have more time and energy to address the needs (both learning and emotional) of the other students in the class. It is felt that the presence of students demonstrating externalizing behaviors have a negative impact on the classroom environment because they: disrupt the learning process, demand a significant amount of time and energy from the teacher, and command a significant amount of teachers' energy while in the classroom, resulting in the needs of others being overlooked.

At no point did teachers state that they considered having the needs of students demonstrating internalizing behaviors removed from the classroom and placed in other academic programs. Teachers shared that they sometimes sent students with internalizing behaviors to the guidance office during class time as a means of providing support for 
their difficulties. Teachers, however, did not appear to be highly invested in removing these students permanently from their classes. It is likely that this practice reflects how students demonstrating internalizing behaviors have little impact on teachers' classroom management. Students who are depressed and withdrawn present few challenges in terms of classroom control, so teachers are not expending a significant amount of time and energy attempting to curb behaviors that disrupt the learning process. It appears as if classroom disruption is highly salient is teachers' decision to refer to special education for a behavior disorder.

Teachers also identified a number of characteristics which may result in a student's needs not being focused upon within the school setting. Among those behaviors and concerns were students who are obese, students who are picked on by other students and have no skills to deal, students who are low performers, students who exist in the middle of the curve and go through the middle of the school, and students who are perpetually late or absent.

\section{Internalizing and Externalizing Behaviors: Relationship to Gender}

A number of teachers indicated that girls do not "misbehave" at the same rate as boys within the school setting: "The girls as a rule, their behavior is better." When questioned why fewer girls were referred to special education for having a behavior disorder, one teacher responded, "My guess is that girls would not warrant being removed from the regular classroom... the behavioral issues are not as serious." In this case, it appears as if the teacher is equating behavioral issues with the behavior disorder classification. Throughout the interviews, it was implied that teachers understand that depression, withdrawal, and social isolation are serious issues which have negative repercussions on students' overall functioning. These behaviors, however, are not considered to be the basis for a behavior disorder. Instead, they are serious behaviors which are addressed only through informal school programs (namely, the guidance counselors). Students demonstrating internalizing behaviors also may not be causing 
disturbances in the classroom, and would not benefit from being removed from the mainstream educational setting. Teachers' understanding of behavior disorders do not appear to reflect students' affective and cognitive issues, but rather reflect a focus on externalizing behaviors.

Teachers may not believe that female's behaviors are as serious because the prevalent conception is that when experiencing difficulties, girls tend to internalize their problems "I think (girls) tend to pull inward." One teacher, however, noted that girls may demonstrate a wide range of behaviors: "With the girls I see one of two behaviors. Either they get really aggressive, or they just totally (engage in) selective withdrawal, or selective incompetence. I see it happening at the middle school where they have decided.. they can't be assertive anymore."

Teachers relayed that within school, girls tend to demonstrate a range of maladaptive internalizing behaviors. Specifically, the teachers reported that girls experiencing difficulties demonstrate the following behaviors: "Girls have eating disorders; come in here crying; get weepy; they look very tired, very depressed." One teacher noted that "It is easy for (girls) to get by because they don't rock the boat. They don't cause any problems, don't get noticed. We just kind of ignore them sometimes, I think, let things slide by." As noted earlier, teachers generally tend to respond to these behaviors by referring the girls to the guidance counselor or other support professionals present in the school system.

When describing the "problem" behaviors of boys, teachers described that males tend to be more physical and aggressive towards others, demonstrating externalizing type behaviors. One teacher reported that "Boys tend to do more acting out," resulting in behaviors that are more apparent and disturbing to both adults and peers in the classroom. One of the most common responses from teachers was that boys tend to manifest their difficulties through acts of physical aggression. As teachers stated: "Boys tend to be 
wilder, a bit more physical." and "Boys tend to act physically. Boys tend to get into fights."

In describing the behaviors of boys, teachers noted that boys generally tended to be more confrontational with peers when having problems. According to one teacher, "Males tend to be cut and dry. If they are angry, they are going to throw a punch and that is going to end it and that is going to be that." "Boys often times, not all of the time, they are much more vocal. They are much more challenging. (The boys) are much more likely to stand up and challenge somebody." On the other hand, teachers reported that girls tend to manifest their difficulties within a web of relationships with peers. They may write notes, talk with friends about difficulties, rely on teachers and school personnel for assistance.

Teachers indicated that the physical aggression was threatening to them, but they generally found the behaviors of boys to be "easier" to address because the boys were direct in stating their feelings and the motivations behind their actions "(With a boy) if you say, what is wrong with you, why are you acting this way? He will tell you and that's it. A boy tells you exactly how he sees it, and if you can intervene to a boy, and you talk about it, that's going to be it, it's over with the end. That's not going to happen with girls." This difference between males and females may reflect the difference in ego development as hypothesized by Hauser et al. (1983). Boys may be acting from within the pre-conformist perspective where it is difficult to maintain the perspective of others whereas girls may generally be acting from a conformist perspective where their understanding of conflicts is more complex based upon their ability to view conflicts from within the perspective of others (Noam \& Boarst, 1994).

A number of teachers stated that notewriting is a common means of communicating with other females when having problems. One teacher noted, "Often times they go with their friends, they do more notewriting. They will write notes in class." Class time, therefore, may be spent communicating with their friends in written forms 
regarding their difficulties. Teachers also reported that generally, girls tend to talk about their problems more, both with school staff and with their friends: "The girls have more of a tendency to talk than the boys," "Overall girls are much more likely to outwardly explore problems that they may be having." As a result, some teachers felt as if girls' problems were a bit more evident than boys because they were willing to discuss them. Girls, however, were less likely to formulate a solution to the problem through the discussion mediated by school staff. Instead, discussions may be seen as grounds for "venting" emotions.

When experiencing severe problems, teachers indicated that the girls typically use the formal support system provided by the school: "or they will get together with their friends and might go down to the guidance office in a group and say we need to talk with a guidance counselor." According to the teachers, visiting with the guidance counselor is a very popular means of addressing girls' concerns, and a way they feel to be very important. Girls often tended to self-refer, and found it to be very important to meet with the guidance counselor when experiencing difficulties: "We have a terrible time with girls trying to make appointments; when you say that they can't see (the guidance counselors) because they are booked, they are the type who will walk right out of the classroom and will walk right down there and sit."

Boys, on the other hand, tend not to want to discuss their problems with school staff. "The boys, if they have a problem a lot of them won't say anything. I think they figure that they'll cover it up." Boys, therefore, tend not to be as willing to express their feelings. Boys also tend not to utilize the formal support network within the school because as one teacher speculates, "With the boys they don't want to (go to the guidance counselor) or they might be embarrassed."

Boys and girls demonstrate significantly different means of addressing their concerns. Girls actively seek out the support of others, while boys generally attempt to avoid discussing their emotions. One teacher also described how it is impossible to have a 
one-on-one conversation with a girl regarding her problems. "(If you ask a girl what is wrong) she will be hemming and hawing, and then another girl will get involved and say, "no, this is what really happened," and then another girl will come up. You can't have a one on one conversation." Girls, therefore, tend to get other girls involved in their issues. These behaviors suggest that girls at this age find relationships to be very important because they provide the structures through which concerns may be addressed. It is possible that females have been socialized to verbalize their feelings, and work through their concerns within the context of their social relationships both with peers and school staff.

In describing the "problem" behaviors of girls, teachers also reported a phenomenon where girls are thought to behave in a way that is more cruel and vicious than boys. As one teacher stated: "Girls are brutal, there is no question." Teachers noted that a "difficult" girl often demonstrates behavior that is more problematic than that of a difficult boy: " Girls, when I have a problem with a girl, they usually give me a really tough problem," and "I think girls at this age are very, very hard to deal with." In describing why girls at this age are difficult to manage, teachers generally reported that they demonstrate externalizing behaviors to a severe degree "these girls are hard, they are 13 going on 25 in some of this behavior. And I don't mean in a sexual way, I mean in a telling off the boss sort of way."

In addition, teachers also reported that girls tend to be cruel within the context of their relationships. It is possible that girls are more embedded in their friendships with others, and have more knowledge of how to hurt each other. According to teachers, girls can be very abusive towards each other, though not in a physical way. Instead, abuse appears to be based upon manipulating the emotions of others: "It is the phone calls, the note writing, the verbal abuse of each other." In describing how girls are cruel, teachers described how they can demonstrate an insensitivity towards the feelings of others. "Girls... stab you in the back, put salt in the wound, and kick you when you are down as 
many times as they possibly can." It is possible that girls can be very cruel towards others because they understand the dynamics of relationships, and are cognizant of which behaviors are most offensive and disturbing to other girls.

Teachers also indicated that girls tend to gang up on other girls and be cruel to them in groups: "Little groups of girls will talk and be cruel and mean in groups," "Girls seem to have the ability to be cruel and to gang up on certain kids." Again, girls seem to rely upon their relationships with others as a means of support. It is possible that they can use this support in a negative way to disturb other students.

When describing the "problem" behaviors of girls, however, teachers described that though they find their behavior to be disturbing, it does not receive equal attention to the behaviors demonstrated by boys. This is because "For the most part, their behaviors don't disrupt the class quite like the boys do." As teachers noted, the nature of abusive behavior is different with boys and girls, and the behavior by girls is much more subtle "With girls it's more fresh, more verbal, rudeness, more subtle things that in some cases are just as bad as what the boys are doing, but you don't pick up on it as readily." Another teacher noted, "With the girls, I think a lot of their aggressive behavior... takes place outside of the classroom."

A number of teachers agreed that they are more lenient when disciplining girls than boys. This difference appears to be based upon two factors: levels of physical aggression and the ability of individuals to "smooth over" relational difficulties. Teachers generally reported that they were most disturbed by aggressive behavior demonstrated within the classroom. Teachers were particularly concerned with behaviors that challenged their personal safety or the safety of students within the classroom Consequently, teachers reported feeling highly motivated to remove physically aggressive individuals from their classrooms. Since many boys demonstrate physical aggression as a means of managing difficulties, teachers are more motivated to refer males than females from their classrooms.

Teachers also indicated that females are better at "smoothing over" relational 
difficulties within the classrooms. Girls reportedly mediate conflicts through the context of their relationships with teachers. Specifically, one teacher reported that when she engages in a discipline issue with a female, she is much more likely to try and make amends for her misbehavior, through apologizes, or talking to the teacher about the situation. Boys, on the other hand, are less likely to discuss the situation and the eventual outcome, leading teachers to use harsher practices with them in the discipline process and when making referrals for special education. While some girls who are demonstrating externalizing disorders may be missed within the referral process, some boys with externalizing disorders may receive undue attention from teachers. This attention may be based on teachers' fears regarding their personal safety, and the boys' relational styles. Teachers' perceptions of students, therefore, appear to mediate the referral process, with teachers considering a number of issues that are not immediately apparent and highly related to gender.

When asked why the "problem" behaviors of girls may tend to not get equal levels of attention from teachers, individuals were cognizant of the flaws in their current practice:

(acting out behaviors) are the ones that get the attention.... I think the other ones unfortunately a lot of the time get forgotten because they are quiet. They don't cause trouble in class...The ones that are outwardly aggressive and screaming out jump out at you and they get your attention all of the time. They interrupt class and disturb you. But the other ones are equally as, or can be, equally as troubled, but that's not the way they seek attention. I think that's why they don't standout as much. I think in the (special ed) room you wouldn't find any (of) those girls who are withdrawn.

Teachers were aware of what types of misbehaviors were likely to result in a referral to special education under the behavioral disorder classification:

I think it is because boys tend to react more violently, so they get the attention first, and they wind up being in that room as opposed to the girls, who may be creating more of a problem but may be doing it quieter, and maybe that's an example of slipping through the cracks. She's rebelling and not doing what she is 
supposed to do, but she is doing it a lot quieter. And she's not creating problems for anybody else. You can do anything you want and if you don't create problems for anybody else, no one says a word. That isn't the way it should be, but that is the way it happens.

If (there are students) who are being taken out, it is the boys. That is because eventually the boys become explosive and aggressive, where the girls might not do that. The boys, or the students you are going to see for special ed, are going to be boys and they are louder, they are more physical, and unfortunately do things in school where the girls are not always going to do that.... I don't think girls needs are met. 


\section{STUDY \#2 \\ Method \\ Participants}

Sixty Middle School and High School teachers from one rural and one semi-rural school district were asked to complete a questionnaire related to practices for referring students to special education for having a behavior disorder. In one school system, permission was obtained from the superintendent of schools to collect data. In that district, teachers were asked to indicate their willingness to participate in the research through completing a form at a middle school faculty meeting and high school faculty meeting. At the high school, teachers who were not at the meeting were then approached individually.

The second school system was the same one used for the qualitative interview study. The researcher was scheduled to attend a faculty meeting to obtain teachers' consent for participation. A snow storm, however, caused the meeting to be canceled. As a result, the researcher asked teachers individually to participate. All 16 teachers who had completed the qualitative interview were included in the second sample, along with a number of other volunteers.

The sample consisted of 60 teachers, equally distributed by sex. Of the original sample, $10 \%$ of the questionnaires were not returned. One teacher resigned his teaching position before the questionnaire was completed, three teachers indicated that they felt uncomfortable or unable to complete the questionnaire as designed, and two teachers simply did not return the questionnaires after repeated reminders from the researcher. Three percent of the sample from the rural school district and $18.5 \%$ of the sample from the semi-rural school district did not complete the questionnaire. When an individual resigned from the study or did not return the questionnaire, the researcher distributed another questionnaire to an individual randomly selected from the "reserve" list of teachers willing to participate. In that manner, completed questionnaires were obtained from 60 
teachers ( 30 male and 30 female). At the semi-rural school, 27 teachers ( 9 male and 18 female) participated in the research. At the rural school, 21 male and 12 female teachers participated.

Average age of individuals completing the questionnaire was 40.1. The average age of male teachers completing the questionnaire was 39.5 and average age of females was 40.6. For the entire sample, the mean for years teaching was 15.42. Mean years teaching for male teachers completing the questionnaire was 15.2 and female teachers was 15.7. The subjects taught by the teachers completing the questionnaires are summarized in Table \#2.

Table \#2

Subjects Taught by Teachers Completing Questionnaires

\begin{tabular}{lc}
\hline Subject & Number of Teachers Completing Questionnaires \\
\hline Language Arts & 19 \\
Social Studies & 13 \\
Math & 13 \\
Science & 11 \\
Physical Education & 5 \\
Living Skills & 5 \\
Spanish & 2 \\
Business Education & 2 \\
French & 1 \\
Health & 1 \\
Computer & 1 \\
\hline
\end{tabular}

* Total is greater than sixty because Middle School teachers teach more than one subject. Instrument

The Achenbach Teacher Report Form "is designed to obtain teachers' reports of their pupils' adaptive functioning and problems in a standardized format" (Achenbach, 1991, p. 3). The Teacher Report Form is designed to differentiate between "disturbed" and "nondisturbed" children, aged 5-18. Five syndromes: withdrawn, somatic complaints, anxious/depressed, social problems, thought problems, attention problems, delinquent 
behavior, and aggressive behavior comprise the Teacher Report Form. Second order factor analyses conducted by Achenbach et. al. (1991) determined an Internalizing grouping (consisting of withdrawn, somatic complaints, and anxious/depressed), and an Externalizing grouping (consisting of delinquent behavior and aggressive behavior). The mean correlation found for the normative sample between Internalizing and Externalizing disorders was .52. For referred samples, the mean Pearson $r$ was .35 between externalizing and internalizing factors.

A test-retest reliability estimate of the Teacher Report Form was found to be satisfactory over a mean time interval of 15 days. For problem subscale scores, $r=.92$. Inter-rater reliability was reported as $r=.54$ for problem scores by teachers across different classroom settings. Criterion-related validity was satisfactory; on all but two problem items, referred children scored significantly higher than nonreferred children $(p<.005)$. Construct validity was also satisfactory; the Achenbach Teacher Report Scales correlated from .80 to .83 with the Connors Conduct Problems Inattention-Passivity, and total problem scores.

Two forms of the questionnaire were distributed to teachers. One questionnaire asked teachers to rate female's behaviors, and the other asked teachers to rate males' behaviors. Each questionnaire contained two parts; one part asked teachers to report their beliefs regarding the characteristics of adolescent male or females experiencing psychological difficulties and the second part asked teachers to describe their current practices when referring male or female students to special education services for behavior disorders.

Thirty teachers ( 15 male and 15 female) completed each form of the questionnaire. The instructions for the different forms are as follows: 
1. Form A. Rate the following behaviors. Which behaviors are most typical of an adolescent male experiencing psychological difficulties?

Form B. Rate each behavior in terms of how important it is in your decision to refer a male student with a suspected behavior disorder to special education. How important is each behavior in your decision to refer?

2. Form A. Rate the following behaviors. Which behaviors are most typical of an adolescent female experiencing psychological difficulties?

Form B. Rate each behavior in terms of how important it is in your decision to refer a female student with a suspected behavior disorder to special education. How important is each behavior in your decision to refer?

No operational definition for behavior disorder or psychological difficulties was provided. Teachers were asked to rate each behavior on a seven point Likert-type scale.

\section{Procedure}

At the semi-rural school district, teachers were individually presented with the questionnaire by the researcher after they indicated their willingness to participate. Informed consent was obtained through a consent form attached to the front of each questionnaire. Teachers at the high school placed their completed questionnaires in a box in the teachers' room. Teachers at the middle school were individually given questionnaires and instructed to send their completed questionnaires to the researcher at the high school through inter-departmental mail. Reminders were placed in teachers' mailboxes two weeks after the questionnaires were distributed. If questionnaires were still not completed by three weeks, the researcher individually reminded teachers.

At the rural school district, teachers were approached individually and asked to participate in the study. Questionnaires were placed in teachers' mailboxes in the teachers' room. Teachers were instructed to pass the completed questionnaire in to the 
research assistant directly or her mailbox in a sealed envelope. The research assistant provided verbal reminders to teachers who had not completed their questionnaires within two weeks.

\section{Results}

Five behavior problem dimension scores were derived for each questionnaire according to instructions in the manual (Achenbach, 1991). A composite score was also calculated for internalizing and externalizing factors. The externalizing factor was comprised of 30 items on the delinquent behavior and aggressive behavior subscales, and the internalizing factor was comprised of 31 items on the withdrawn, somatic complaints, and anxious/depressed behavior subscales. These composite data were then analyzed through the use of two 2 (gender of student) $\times 2$ (Test) repeated measures ANOVAs. The Test variable represents the two guiding questions of each questionnaire: which behaviors are indicative of psychological difficulties and which behaviors would lead to a special education referral for a behavior disorder. The first ANOVA analyzed externalizing behavior and the second analyzed internalizing behavior. A MANOVA was determined to be inappropriate because the internalizing and externalizing scores were on a different metric and were comprised of unique item sets.

Additional 2 (sex of teacher) 2 (score on subfactor) ANOVAs were calculated for each of the 5 subscales (withdrawn, anxious/depressed, somatic complaints, delinquent behavior and aggressive behavior). In addition, the correlations between subscales were calculated. 
TABLE \#3

Means and Standard Deviations for Female Students on Subscales and Factors

\begin{tabular}{lll} 
& Females Psychological Difficulties & Females Referral \\
\hline Withdrawal & 33.73 & 33.87 \\
& $(6.45)$ & $(8.27)$ \\
Somatic Complaints & 28.83 & 27.27 \\
& $(7.47)$ & $(9.28)$ \\
Anxious/Depressed & 59.85 & 59.83 \\
& $(11.89)$ & $(16.66)$ \\
Internalizing & 122.42 & 120.97 \\
& $(19.16)$ & $(30.97)$ \\
Delinquent Behavior & 44.23 & 43.08 \\
& $(7.11)$ & $(10.42)$ \\
Aggressive Behavior & 102.42 & 96.33 \\
& $(16.26)$ & $(17.74)$ \\
Externalizing & 146.65 & 139.42 \\
& $(21.76)$ & $(26.46)$ \\
\hline
\end{tabular}

TABLE \#4

Means and Standard Deviations for Male Students on Subscale and Factors Males Psychological Difficulties Males Referral

Withdrawal $\quad 30.73$

(6.75)

Somatic Complaints 23.15

(8.81)

Anxious/Depressed $\quad 47.92$

(11.39)

Internalizing

101.8

(23.26)

Delinquent Behavior 44.72

(6.56)

Aggressive Behavior 109.4

(13.1)

Externalizing
34.1

(8.31)

29.6

(10.71)

61.53

(17)

125.23

(32.66)

42.37

(9.16)

97.97

(19.11)

140.33

(27.39)

I tests were calculated to compare internalizing and externalizing behaviors for students experiencing psychological difficulties and students referred to special education for a behavior disorder. Specifically, $t$ tests compared internalizing and externalizing 
behaviors for: males experiencing psychological difficulties; males referred to special education; females experiencing psychological difficulties; and females referred to special education.

The ANOVA for externalizing behavior revealed non-significant effects for gender, $F(58,1)=.74, p>.05$, eta squared $=.013$. Significant main effects were found for the "test" variable, $F(58,1)=7.9, p<.05$, eta squared $=.12$. Teachers indicated that both males and females demonstrated significantly more externalizing behaviors when experiencing psychological difficulties than when being referred to special education for a behavior disorder. The interaction was not found to be significant, eta squared $=.013$.

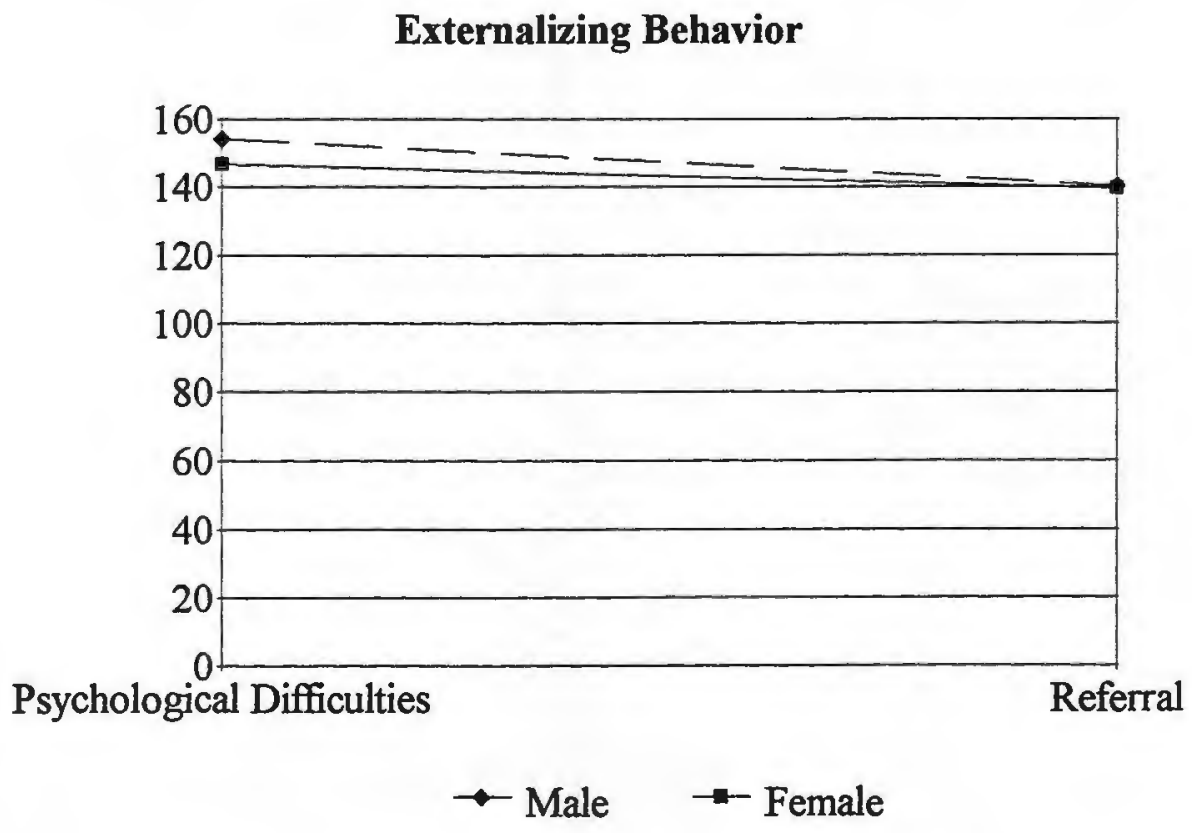

Figure \#1

The ANOVA for internalizing behavior revealed non-significant effects for gender, $F(58,1)=2.36, p>.05$, eta squared $=.039$. The main effect for the "test" variable was found to be significant, $F(58,1)=5.87, p<.05$, eta squared $=.092$. Individuals referred to special education for a behavior disorder demonstrate significantly higher levels of internalizing behaviors than individuals experiencing psychological difficulties. There was a significant 
test by gender interaction effect, $F(58,1)=7.52, p<.05$, eta squared $=.115$. A follow up $\mathrm{t}$ test determined that males referred to special education demonstrated significantly greater levels of internalizing behavior than males experiencing psychological difficulties, $(\mathrm{t}=$ $3.59, \mathrm{p}<.05)$. The follow up $\mathrm{t}$ tests indicate that gender differences in prevalence are not reflected in importance for referral.

Figure \#2

\section{Internalizing Behavior}

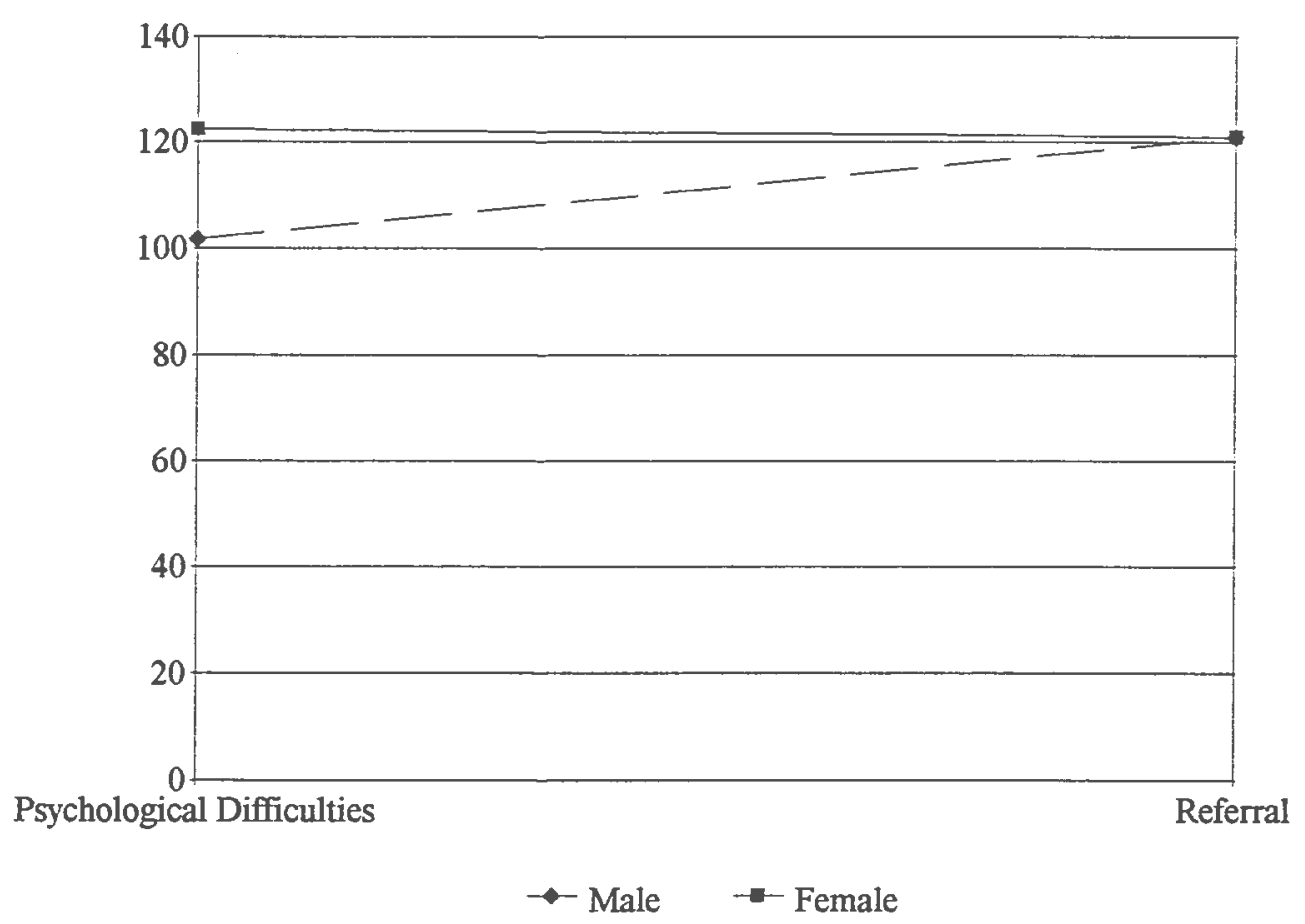

ANOVAs were also completed for individual subscale scores. A 2 (gender of student) $\times 2$ (test scores on somatic complaints subscale) ANOVA determined a significant interaction between gender of student and test, $F(1,58)=6.37, p \leq .05$, eta squared $=.13$. Follow up $\mathrm{t}$ tests determined that teachers reported that female students experiencing psychological difficulties demonstrate greater levels of somatic complaints than male students experiencing psychological difficulties, $\mathrm{t}=2.69, \mathrm{p} \leq .05$. In addition, 
male students referred to special education demonstrate significantly higher rates of somatic complaints than male students experiencing psychological difficulties, $t=2.8$, $\mathrm{p} \leq .05$.

A 2 (gender of student) $\times 2$ (test score on anxious/depressed subscale) ANOVA determined significant differences exist between students' scores on the anxious/depressed subscale score, $\mathrm{E}(1,58)=8.65, \mathrm{p} \leq .05$, eta squared $=.13$. Students referred to special services for a behavior disorder demonstrate significantly higher levels of anxious/depressed behavior than individuals experiencing psychological difficulties. A significant interaction was found, $E(1,58)=8.7, p \leq .05$, eta squared $=.13$. Follow up $t$ tests concluded that girls experiencing psychological difficulties demonstrate significantly higher levels of anxious/depressed behavior than boys, $\mathrm{t}=3.97, \mathrm{p} \leq .05$. In addition, another follow up $t$ test concluded that boys referred to special education for a behavior disorder demonstrate significantly higher levels of anxious/withdrawn behaviors than boys experiencing psychological difficulties, $t=4.09, \mathrm{p} \leq .05$.

No other gender $\mathrm{x}$ subscale score ANOVA produced significant results. Specifically, males and females demonstrated generally equivalent rates of withdrawn, aggressive, and delinquent behaviors when experiencing psychological difficulties and when being referred to special education for a behavior disorder.

Additional ANOVAs were calculated to determine significant differences on student ratings between male and female teachers. Subscale scores were compared to determine if significant differences existed between the male and female teachers' ratings of students. All subscale scores were found to be analogous for male and female teachers with the exception of the somatic complaints subscale on the psychological difficulties portion of the questionnaire. A 2 (gender of teacher) $\times 2$ (score on somatic complaints subscale) was found to be significant, $F(1,58)=6.43, p \leq .05$. Female teachers reported students as demonstrating higher levels of somatic complaints than male teachers. 
Table \#5

Mean Scores of Male and Female Teachers on Subscales and Factor Scores.

Total Psych. Difficulties Withdrawal

Male Teachers

32.07

Total Psych. Difficulties Somatic Complaints 28.68

Total Psych. Difficulties Anxious/Depressed 53.27

Total Psych. Difficulties Internalizing

Total Psych. Difficulties Delinquent Beh.

Total Psych. Difficulties Aggressive Beh.

Total Psych. Difficulties Externalizing

Total Referral Withdrawal

Total Referral Somatic Complaints

Total Referral Anxious/Depressed

Total Referral Internalizing

Total Referral Delinquent Behavior

Total Referral Aggressive Behavior

Total Referral Externalizing
114.02

44.97

108.17

153.13

33.5

28.27

58.07

112.83

43.03

99.87

142.9
Female Teachers

32.4

23.3

54.5

110.2

43.98

103.65

147.63

34.47

28.6

63.3

126.37

42.42

94.43

136.85

Table \#6

Standardized T scores for Males

$\begin{array}{lll} & \text { Internalizing } & \text { Externalizing } \\ \text { Psychological Difficulties } & 45.6 & 51.8 \\ \text { Referral } & 50.6 & 50.2\end{array}$

Scores were standardized across the sample and converted into $\mathrm{T}$ scores. I tests were utilized to compare rates of internalizing and externalizing behaviors for males, females, and the entire sample. A t-test determined that males experiencing psychological difficulties manifest significantly more externalizing than internalizing behaviors, $t=2.85$, $\mathrm{p}<.01$. A $\mathrm{t}$ test also determined that males referred for special education demonstrate generally equivalent rates of internalizing and externalizing behaviors. 
Table \#7

Standardized $t$ scores for Females

$\begin{array}{lll} & \text { Internalizing } & \text { Externalizing } \\ \text { Psychological Difficulties } & 54.5 & 48.2 \\ \text { Referral } & 49.3 & 49.8\end{array}$

A T test determined that females experiencing psychological difficulties demonstrate significantly more internalizing than externalizing behaviors, $t=2.77$, $\mathrm{p}<.01$. Females referred to special education for having a behavior disorder demonstrate generally equivalent rates of internalizing and externalizing behaviors.

Correlations were calculated between subscale scores to determine the relationship among subscales and factors. The correlations are summarized in Table \#8. 

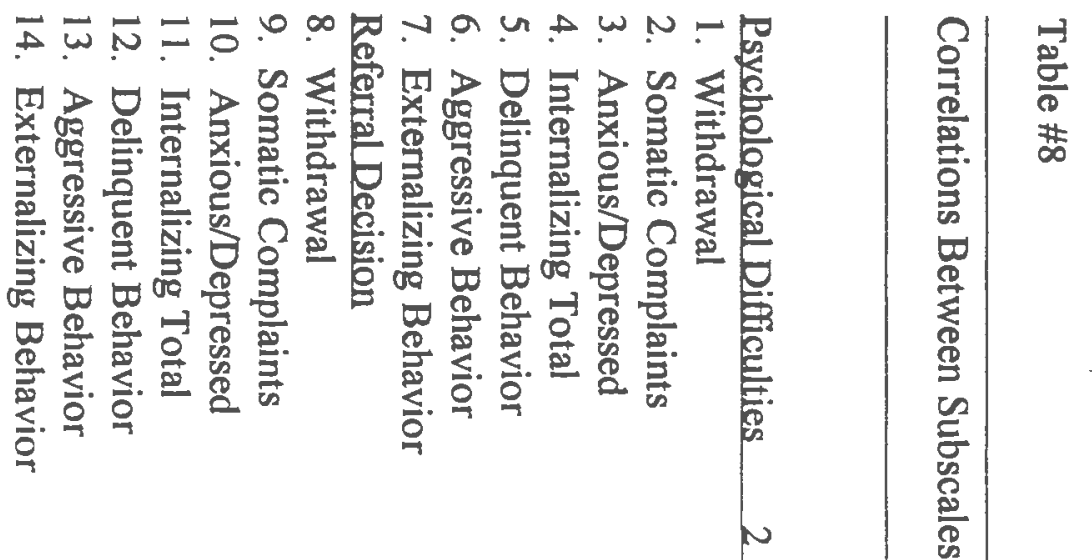

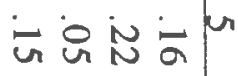

$$
\begin{aligned}
& \text { ํํำำำ } \\
& \text { 웡유 }
\end{aligned}
$$

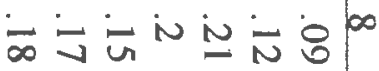

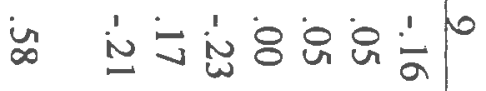

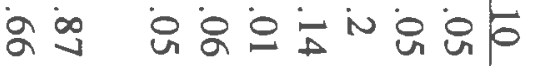

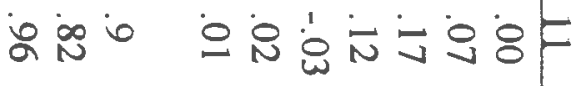

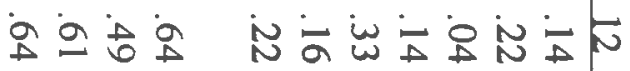

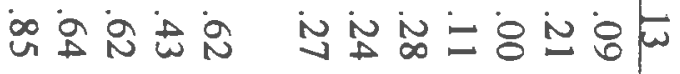



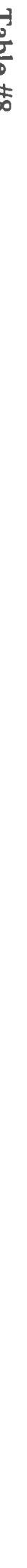




\section{DISCUSSION}

The quantitative findings were generally consistent with the hypotheses. Teachers' ratings indicated that students experiencing psychological difficulties demonstrate a significantly greater number of externalizing behaviors than students who are referred to special education for having a behavior disorder. This result suggests that teachers are likely to interpret externalizing behaviors (i.e., delinquent and aggressive behaviors) as being indicative of psychological difficulties in students. Teachers also do not perceive greater levels of externalizing behaviors leading to a special education referral. Instead, it appears as if other factors are utilized as the basis for referral decisions in the special education decision making process.

Teachers' results indicate that males experiencing psychological difficulties demonstrate greater levels of externalizing behaviors than females, a result that corresponds with the hypotheses and previous research. Teachers reported that male and female students referred to special education for having a behavior disorder demonstrate equivalent rates of externalizing behavior. This result indicates that teachers perceive students as manifesting their difficulties in patterns related to gender, yet these differences are not utilized in the special education referral process. Instead, a relatively consistent standard is applied in referral decisions.

Teachers also reported that students who are referred to special education for having a behavior disorder demonstrate significantly greater levels of internalizing behaviors than students who are experiencing psychological difficulties. The meaning of this main effect was clarified by the significant interaction and follow-up analyses. Specifically, males referred to special education demonstrated significantly higher levels of internalizing behaviors than males experiencing psychological difficulties. There were no significant differences for females on internalizing behaviors when experiencing psychological distress and when being referred to special education as having a behavior disorder. Teachers also reported that females experiencing psychological difficulties 
demonstrate significantly more internalizing behaviors than males. This result indicates that teachers recognize that males and females manifest their difficulties in different manners, but referrals to special education are based upon the same criteria for each gender.

The results of the ANOVAs with specific subscales indicate that teachers perception of somatic complaints vary by gender. Teachers perceive male and female students who are referred to special education for having a behavior disorder as demonstrating the analogous levels of somatic complaints. Teachers also report that females experiencing psychological difficulties demonstrate similar levels of somatic complaints as females referred to special education for having a behavior disorder. Teachers, however, report that males referred to special education for having a behavior disorder demonstrate significantly higher levels of somatic complaints than males who are experiencing psychological difficulties. Thus, teachers feel that males' somatic complaints are salient cues utilized in the decision to refer students to special education.

The depression/anxious subscale was also reflected teachers' views regarding the differential behaviors of male and female students. Specifically, teachers reported that individuals referred to special education demonstrated significantly higher rates of anxious depressed behaviors than individuals experiencing psychological difficulties. A significant difference was found between the internalizing scores of males: males referred to special education demonstrated higher levels of anxious/depressed behavior than males experiencing psychological difficulties. Females, on the other hand, demonstrated analogous rates of anxious/depressed behavior when experiencing psychological difficulties and when referred to special education. In addition, it was reported that females experiencing psychological difficulties demonstrated significantly higher levels of anxious/depressed behavior than males experiencing psychological difficulties. These results suggest that teachers find males' anxious/depressed behavior to be salient cues to be utilized in the special education referral process. 
Correlations calculated between subscales also determined that teachers did not perceive withdrawal $(r=.686)$ as being as highly correlated to internalizing behaviors as somatic complaints $(r=.822)$ and anxious/depressed behavior $(r=.913)$ for students experiencing psychological difficulties. These results suggest that teachers may not perceive withdrawn behavior as being highly indicative of students' psychological difficulties. On the other hand, the analyses determined that teachers felt withdrawn behavior was highly correlated $(r=.899)$ with internalizing behaviors in their importance ratings regarding student referral practices. Consequently, withdrawn behavior is a salient cue utilized in the decision to refer a student to special education for a behavior disorder.

For both the internalizing set of subscales and the externalizing set of subscales, the internal pattern of correlations among subscales within a set is higher for referral decisions than for psychological difficulties. The correlation between internal and external scales is also much higher for referral (.660) than for psychological difficulties (.083). For referral, teachers are consistent in using the higher end (or middle or low end) across all the different items and subscales. For example, a teacher who thinks internal behaviors are important for referral is likely to think external behaviors are as well. In the case of psychological difficulties, however, teachers report more differentiated perceptions of "typicality" of internalizing and externalizing behaviors, leading to a much lower correlation.

Through the $t$ tests conducted, results indicate that males experiencing psychological difficulties demonstrate significantly greater numbers of externalizing than internalizing behaviors, a result that corresponds with previous research. Males referred to special education, however, demonstrate analogous rates of internalizing and externalizing behaviors. This result suggests that teachers consider internalizing and externalizing behaviors to be equally salient in the decision making process.

Results of $t$ tests also determined that females experiencing psychological difficulties demonstrate a significantly greater number of internalizing than externalizing 
behaviors, a result that corresponds with previous research and the results of the qualitative study. Again, teachers report that internalizing and externalizing behaviors are equally salient in the decision making process when referring students to special education for a behavior disorder. 


\section{DISCUSSION OF RESULTS FROM BOTH STUDIES}

The results of the quantitative and qualitative investigations strongly support the view that teachers recognize that males and females generally demonstrate differential patterns of behavior when experiencing psychological difficulties. Specifically, males are more likely than females to demonstrate externalizing behaviors and females tend to demonstrate internalizing behaviors when experiencing psychological difficulties.

In the case of externalizing behaviors, teachers indicated that these behaviors typically centered around disruptive, aggressive, and physically challenging behaviors perceived as being disruptive within the classroom context. Though some females demonstrate externalizing behaviors when experiencing psychological difficulties, the majority of individuals presenting with disruptive behavior in the classroom and school setting are male, according to teacher interviews.

Females, on the other hand, tend to demonstrate internalizing behavior when experiencing psychological difficulties. According to teacher report, internalizing behaviors include withdrawal, depression, isolation from friends and school staff, as well as eating disorders. Teachers reflected that adolescent girls experiencing difficulty may manifest these types of behaviors in reaction to the social construction of gender. It is possible that girls are taught to suffer silently and not cause a disturbance for others. Teachers reported that modern culture tends to reward passivity in girls, consequently, adolescent girls may manifest their difficulties according to the societal norms they have internalized in the process of forming an identity, a notion supported by research conducted by Brown and Gilligan (1992). Girls, however, are also apparently socialized to be more effective in their help-seeking behavior when experiencing difficulties, more socially mature, and more able to deal with their difficulties within the context of existing relationships.

The findings of the qualitative and quantitative studies did not concur in regards to the types of students referred to special education for a behavior disorder. Qualitative 
results indicated that teachers tend to refer disruptive male students who cause a disturbance within the ecosystem of the classroom. When interviewed, teachers stated that males and females are not referred at equal rates and are not referred for analogous behaviors.

The results of the quantitative study indicate that teachers tend to use the exact same criteria for both genders when referring students to special education. Specifically, teachers appear to maintain a decision making threshold for both internalizing and externalizing behaviors that are held constant for both males and females. Consequently, if a male student demonstrates a significant level of internalizing behaviors, they will be referred to special education. Conversely, if a female demonstrates a significant level of externalizing behavior, they too will be referred.

Based upon the results of the questionnaire, teachers reported males who demonstrate internalizing type behaviors are referred to special education for a behavior impairment.. Teachers reported that internalizing behaviors are more typical in females, but the level of internalizing behavior is equally important across gender in the decision to refer a student to special education for a behavior disorder. Specifically, males referred for services tended to demonstrate significantly higher scores on the somatic complaints and anxious/depressed subscale than males experiencing psychological difficulties. It is possible that teachers are more likely to recognize depressed/withdrawn behavior as being indicative of a behavioral impairment in males because that type of behavior deviates from teachers' perceptions of "normal" problem behaviors. This dissonance between expected and perceived behaviors may lead teachers to make referrals due to their concern over male students' behaviors, and the belief that the special education referral process is to be used for all students whose behaviors cross a threshold, regardless of gender. It is crucial to note that teachers do not report that they emphasize internalizing behaviors more for males than females in the referral process. Instead, it appears that teachers maintain a gender blind threshold that is held constant for all students, regardless of sex. 
Within the interviews, teachers did not express concern for males demonstrating internalizing behaviors. In addition, teachers did not explain their practices as being based upon a gender blind threshold. Instead, they reported how the classification has been constructed within their school system, and the disruptive types of students who are thought to be appropriate for the referral process and receipt of services. It is interesting to note that the internalizing behaviors of males are perceived as being worthy of concern within the classroom, as evidenced by teachers' reported referral practices.

Results of the qualitative study indicate that the behavior impairment classification is primarily viewed as a means of addressing the behaviors of disruptive types of students. When interviewed, teachers indicated that they generally tend to refer disruptive students to special education for consideration under the behavior impairment classification. Specifically, "typical" students with behavioral impairments tend to demonstrate: impulsivity/attention issues, peer difficulties, aggressive behavior, poor emotional management skills, talking out behaviors, and non-compliance with school rules. Throughout the interviews, teachers demonstrated a great degree of concurrence in specifying that they perceived the behavior impairment category as a classification designed to meet the needs of students who caused a disruption within their classrooms. At no point did teachers report that internalizing behaviors was considered relevant within the special education referral process, except when it negatively impacts academic performance.

Though teachers reported that they utilize analogous referral patterns for male and females on the questionnaire portion of the study, in interviews they readily disclosed that their actual process is mitigated by gender based issues. Specifically, teachers reported that they tend to judge males by harsher criteria than females. Based upon the interpretation of the interview results, teachers report that within the classroom context, the same criteria are used for males and females when deciding who to refer to special education for a behavior disorder. Males, however, are judged more harshly than females, 
as reported by teachers. Within the classroom context, males are referred more often because teachers are threatened by their aggressive behaviors which are physically challenging within the classroom environment. Teachers are highly motivated to refer male students who they feel threaten their personal safety: In addition, teachers indicated that male students are not as adept as smoothing over relational difficulties as females. If females experience a conflict with a teacher in the classroom, they are likely to make amends or apologize for their misbehavior. The disparity between male and female students' behaviors may again be attributable to the social construction of gender and how this construction is manifested during adolescence. It is possible that adolescent females maintain a primary focus on relationships and pleasing others. Consequently, within a classroom they will be motivated to maintain a positive relationship with the teacher. Males, on the other hand, may not be facing the same developmental tasks due to a cultural norm for males that does not emphasize the importance of not hurting the feeling of others and maintaining a relationship at the expense of one's personal happiness. As a result, males may not attempt to make amends, a factor which leads teacher to judge them more harshly.

Consequently, in terms of referral practices, the results of the qualitative and quantitative study do not correspond. This discrepancy may be attributable to a number of factors. First, the structure of the questionnaire may not have "tapped" teachers' actual practices. The scenario presented, and behaviors outlined may not accurately reflect situations/behaviors faced by teachers in the referral process. Second, teachers may utilize one set of criteria on a conceptual level and another on a practical level. When asked to describe practices in general terms, teachers may elucidate a policy that is gender neutral. In practice, however, teachers may be much more reactive in their decisions taking into account a myriad of factors that influence their referral decisions. The results of the questionnaire may reflect what teachers would do in an ideal setting, and the results of the qualitative study may reflect their current practices. 
Throughout the interviews, teachers indicated that the school system tended to utilize informal support mechanisms for individuals demonstrating internalizing type behaviors, Many students who are withdrawn or depressed are referred to guidance, where they may attend individual meetings or be placed in a group. No formal type of identification process was noted, no formalized assessment process used, and no clear program was in place to ensure that these types of students were able to function successfully within a mainstream academic environment. Furthermore, the informality of the process was accompanied by a lack of attention to providing sufficient resources to meet the needs of students with internalizing behaviors.

When discussing the referral process, teachers readily reported that the primary benefit of making a special education referral was to achieve a level of respite from the student's disruptive behavior within the classroom environment. Through the interviews, it was apparent that teachers are highly bothered by students who negatively impact the classroom environment through their behavior. Teachers noted that they were most concerned with students who were physically threatening, disruptive in class, or those whose behavior monopolized the teachers' time, resulting in the education of the other students being shortchanged. Boost and the special education processes were viewed by teachers as the mechanisms in place to address disruptive types of students.

It is possible that the behavior impairment classification is a construct that has been interpreted in the schools in a way most suitable to meet the needs of school staff. Teachers and administrators both report being greatly bothered by disruptive types of behaviors which negatively impacts the classroom environment. Teachers also shared that students experiencing difficulties who tend to withdraw and isolate themselves, tend not to disturb the equilibrium of the classroom. Consequently, the behavior impairment classification may be construed to meet the needs of teachers who are frustrated and overwhelmed by disruptive students. 
As a result, current practice may overlook the needs of adolescent females who represent the majority of those students who demonstrate internalizing behaviors. Teacher interviews indicated that students with internalizing issues often times get "missed" within classroom environments. Students who are withdrawn and isolated tend to exist silently in classrooms, not making waves or engaging in behaviors that necessitate teachers' attention. Consequently, their behaviors may not be as salient to teachers, which may result in their maladaptive behaviors being overlooked.

Current practice may simply respond to the needs of school staff and may not adequately address the wide range of maladaptive behavior demonstrated by students that are worthy of intervention. Internalizing behaviors should be recognized as being as maladaptive as externalizing behaviors, even though they are not as discernible and disruptive within the school context. Current practice should reflect the differential types of behaviors demonstrated and take a more comprehensive approach to providing appropriate intervention services.

Schools, therefore, need to develop a comprehensive means of addressing the continuum of maladaptive behaviors within the school environment. Internalizing and externalizing behaviors should be considered as equally worthy of intervention within the classrooms. Teachers should be educated to recognize the signs of internalizing behaviors (i.e. depression, withdrawal, anxiety, etc.) and taught to make referrals even though these behaviors may not be disruptive within their classrooms.

Schools should develop formal identification and treatment/support programs in place to ensure that students' internalizing behaviors are addressed. Current practices reveal that students with internalizing issues are commonly referred to the guidance counselors, who maintain large caseloads and informal means of addressing student difficulties. The special strengths of females to seek out peer and professional support should not be relied upon as an alternative to formally provided services. School systems should develop formal programs that are designed to meet the needs of students with 
internalizing issues. Appropriate interventions may include referrals to a social worker for therapy or case management services, or the provision of a group designed to address issues related to depression and or anxiety.

When inspecting the results of the two studies conducted, however, it is crucial to be cognizant of the limitations of the methods utilized. The qualitative study was conducted at only one site, resulting in an understanding of how the referral process is utilized in one setting. It is likely that interviews at another site would have provided a broader understanding of current practices within school settings. It is felt, however, that the results obtained at one site are "representative" of teachers' current referral practices around the behavior disorder classification. Though results reflect current practice at one school, with a limited set of individuals, it is believed that the "core" themes found through the interviews would be obtained in other settings. Another limitation pertains to the fact that the interviews were conducted at a school where the researcher had been a student. As a result, teachers' responses may have been influenced by the existence of a prior relationship. In addition, it would have been helpful to have anothe reader process the interview texts in order to see if they perceived similar themes as emerging. The qualitative analysis was based upon one reasercher's understanding of the interview process and transcripts. Consequently, the results reflect only one person's understanding of the phenomenon under investigation.

The limitations of the quantitative results center upon a small sample that was obtained at two sites. Again, it is probable that the use of other sites would have provided a more comprehensive look at current referral practices in school settings. The simulation employed in the quantitative study may not have approximated actual teacher practices. The Federal Definnition for behavior disorder also does not directly correspond with Achenbach's (1991) definition of behaviors determined to be "clinically significant." Consequently, the Achenbach instrument may identify students whose behaviors are considered to be highly aberrant when compared to other same sex peers. The 
Achenbach, however, may not clearly delineate which students qualify for special education services under the current Federal Definition. Another limitation of the quantative study focuses on the difficulty in comparing the externalizing and internalizing scales. Both broad band factor scores were comprised of unique item sets. Consequently, the scales were placed on a different metric and were considered to be unique. As a result, it was difficult to compare these factor scores as they were based upon separate constructs.

Despite the limitations, the results suggest some important conclusions about schools' current practices for students with behavior disorders. The needs of students who demonstrate internalizing behaviors should not be considered invisible within school settings. Instead, their silence and passivity should serve as warning flags for greater difficulties worthy of intervention. Future research should focus upon identification programs which adequately screen and identify students with serious internalization issues, including more effective preparation and support of classroom teachers as primary referral agents. In addition, future studies should study the efficacy of school-wide programs designed to meet the needs of all students with mental health needs. Another important topic for future research is how limited school resources may be utilized so that the needs of these students are met within current programs. Research should also focus on internviewing school administrators and guidance counselors as to their current practices around special education referrals for the behavior disorder classification. Many referrals are currently made by administrators and guidance counselors, not classroom teachers. It is crucial, therefore, to explore how administators are currently making referrals in order to understand the flow of students from mainstream classrooms to special education settings for services under the behavior disorder classification. Finally, research should also focus on interventions or support systems which may be utilized with classroom teachers so that they are given tools to utilize as they attempt to manage the behavior of students with externalizing issues while recognizing that the psychological needs of 
students demonstrating internalizing disorders should be given equal consideration within the classroom. 


\section{REFERENCES}

Achenbach, T.M. (1991). Manual for the teacher's report form and 1991 profile. Burlington, VT: University of Vermont Department of Psychiatry.

Achenbach, T.M., \& Edlebrock, C.S. (1979). The child behavior profile II: Boys aged 12-16 and girls aged 6-11 and 12-16. Journal of Consulting and Clinical Psychology, 47, 223-233.

Achenbach, T.M., \& Edlebrock, C.S. (1983). Taxonomic issues in child psychopathology. In T.J. Ollendick \& M. Hersen I (Eds.). Handbook of child psychopathology (pp. 65-93). New York: Plenum Press.

Achenbach, T.M., Howell, C.T., Quay, H.C., \& Connors, K.C. (1991). National survey of problems and competencies among four to sixteen year olds: Parents' reports for normative and clinical samples. Monographs of the Society for Research in Child Development, 56 (3, serial No. 225).

Algozzine, B. (1977). The emotionally disturbed child: Disturbed or disturbing? Journal of Abnormal Child Psychology, 5, 205-211.

Algozzine, B., Christenson, S., \& Yssledyke, J.E. (1982). Probabilities associated with referral-to-placement process. Teacher Education and Special Education, 5, 19-23.

Algozzine, B., Ruhl, K., Ramsey, R., Wood, F., Phillips, V., Maheady, L., Skiba, R., Test, D., Cooke, N., \& Walker, H. (1991). Behaviorally Disordered? Assessment for Identification and Instruction. Working with Behavioral Disorders, CEC mini-library. Council for Exceptional Children, Reston, VA. ERIC Document Reproduction No 333 660.

Borko, H., \& Caldwell, J. (1982). Individual differences in teachers' decision strategies: An investigation of classroom organization and management decisions. Journal of Educational Psychology, 74, 598-610.

Brown, L.M., \& Gilligan, C. (1994). Meeting at the Crossroads: Womens' psychology and girls' development. Cambridge: Harvard University Press.

Callihan, K. (1994). Wherefore art thou, Juliet? Causes and implications of the male dominated sex ration in programs for students with emotional and behavioral disorders. Education and Treatment of Children, 17, 228-243. 
Cullinan, D., Epstein, M.H., \& Kauffman, J.M. (1984). Teachers' ratings of students' behaviors: What constitutes behavior disorder in schools? Behavioral Disorders, 10. 9-19.

Cullinan, D., Epstein, M.H., \& Lloyd, J.W., (1983). Behavior Disorders of Children and Adolescents. Englewood Cliffs, NJ: Prentice-Hall.

Edgar, E., \& Hayden, A. (1985). Who are the children special education should serve and how many children are there? The Journal of Special Education, 18, 523-539.

Epstein, M.J., Kauffman, J.M., \& Cullinan, D. (1985). Patterns of maladjustment among the behaviorally disordered II: Boys aged 6-11, boys aged 12-18, girls aged 6-11, and girls aged 12-18. Behavioral Disorders, 10, 125-135.

Hauser, S., Jacobson, A., Noam, G., \& Powers, S. (1983). Ego development and self-image complexity in early adolescence: Longitudinal studies of diabetic and psychiatric patients. Archives of General Psychiatry, 40, 325-332.

Hayden-Mc Peak, C., Gaskin, S.T., \& Gaughan, L.K. (1993, April). Bad Boys, Good Girls: A Review of the Research on Gender Differences of Assessment, Child Rearing and Educational Practice. Paper presented at the Annual Convention of the Council for Exceptional Children, San Antonio, TX.

Jennings, K.D., Mendlesohn, S.R., May, K., \& Brown, G.M. (1988). Elementary students in classes for the emotionally disturbed: Characteristics and classroom behavior. American Joumal of Orthopsychiatry, 58, 65-76.

Kauffman, J.M., McCullough, L.L., \& Sabornie, E.J. (1984). Integrating exceptional students: special problems involving the emotionally disturbed/behaviorally disordered. British Columbia Journal of Special Education, 8, 201-210.

Kaufman, A.A., Swan, W.W., \& Wood, M.W. (1980). Do parents, teachers and psycho-educational evaluators agree in their perceptions of black and white emotionally disturbed? Psychology in the Schools, 17, 185-191.

Martin, R. (1972). Student sex and behavior as determinants of the type and frequency of teacher-student contacts. Journal of School Psychology, 10. 339-347.

Mattison, R.W., Morales, J., \& Bauer, M.A. (1991). Elementary and secondary socially and/or emotionally disturbed girls: Characteristics and identification. Journal of School Psychology, 22, 121-134.

Miles, M.B., \& Huberman, A.M. (1994). Qualitative Data Analysis. Thousand Oaks, CA: Sage Publications. 
Miller, L.C. (1972). School Behavior Checklist: An inventory of deviant behavior for elementary school children. Journal of Consulting and Clinical Psychology, 38 , 134-144.

Mullen, J.A, \& Wood, F.H. (1986). Teacher and student ratings of the disturbingness of common problem behaviors. Behavioral Disorders, 11, 168-176.

Noam, G.G., \& Borst, S. (1994). Developing meaning, losing meaning: Understanding suicidal behavior in the young. New Directions for Child Research, 64 , 39-54.

Packer, M.J., \& Addison, R.B. (1989). Introduction. In M.J. Packer \& R.B. Addison (Eds.),_Entering the circle: Hermeneutic investigation in psychology (pp. 13-36). Albany: State University of New York.

Pearcy, M.T., Clopton, J.R., \& Pope, A.W. (1993). Influences on teacher referral of children to mental health services: Gender, severity, and internalizing versus externalizing problems. Journal of Emotional and Behavioral Disorders, 1, 165-169.

Redmore, C., \& Loevinger, J. (1979). Ego development in adolescence: Longitudinal studies. Journal of Youth and Adolescence, 8, 1-20.

Rhodes, W.C. (1967). The disturbing child: A problem of ecological management. Exceptional Children, 33, 444-455.

Rhodes, W.C. (1970). A community participation of analysis of emotional disturbance. Exceptional Children, 36, 309-314.

Rhodes, W.C., \& Paul, J.L. (1978). Emotionally disturbed and deviant children. Englewood Cliffs, NJ: Prentice-Hall.

Shinn, M. (1987). Special education referrals as an index of teacher tolerance: Are teachers imperfect tests? Exceptional Children, 54 (1), 32-40.

Stockard, J. (1980). Sex inequities in the experience of students. In J. Stockard, P.A. Schmuck, K. Kempner, P. Williams, S.K. Edson \& M.A. Smith (Eds.), Sex equity in education. (pp. 11-48). New York: Academic Press.

U.S. Department of Education (1990). Individuals with Disabilities Education Act. Washington, DC.

U.S. Department of Education (1992). Fourteenth Annual Report to Congress on the Implementation of the Individuals with Disabilities Education Act. Washington, DC: Office of Special Education and Rehabilitative Services. 
Vitale, M.R. (1983). Using multidimensional scaling and unfolding to explore teacher perceptual biases for selecting special education referral strategies. Journal of Experimental Education, 51, 134-141.

Wood, J. (1981). Perspectives for a New Decade: Education's Responsibility for Seriously Disturbed and Behavior Disordered Children and Youth. CEC/CCBD National Topical Conference on the SED. August 13-15, Minneapolis, MN.

Woolfolk, R.L., Sass, L.A., \& Messer, S.B. (1988). Introduction to hermeneutics. In R.L. Woolfolk, L.A. Sass \& S.B. Messer (Eds.), Hermeneutics and psychological theory: Interpretive perspectives on personality, psychotherapy, and psychopathology, (pp. 2-26). New Brunswick:Rutgers University Press.

Ysseldyke, J., \& Thurlow, M. (1984). Assessment practices in special education: Adequacy and appropriateness. Educational Psychology, 9, 123-136. 


\section{APPENDLX A}

\section{Teacher Interview}

1. Describe a "typical" student with a behavior disorder.

2. What are some behaviors students engage in that serve as a red flag to indicate to you that they have a behavior disorder?

Do you think these behaviors differ for males and females?

Describe the "typical" problem behaviors of an adolescent male.

Describe the "typical" problem behaviors of an adolescent female.

3. Describe your practices when referring students for special education services for having a behavior disorder. What type of student are you likely to refer? Why are you likely to refer that type of student?

4. What classroom behaviors will most likely cause you to refer a student to special education services as having a behavior disorder?

Why are these behaviors of greater concern than other "problem" behaviors that might be demonstrated by students in your classroom?

5. What "problem" behaviors are you least likely to refer in a BD special education referral?

Why are these concerns of less concern than others?

6. What is the benefit from referring a student to special education for having a behavior disorder? Do you benefit? If so, how?

7. How does the referral to classification system work in your school?

Do you think the current system is effective? Why or why not?

Who do you think the current system misses?

8. What types of classroom behaviors do you find most difficult to deal with?

Why are these behaviors most difficult to deal with?

9. Do you think you "overlook" any students in your classroom? What are the typical characteristics of these "overlooked" students?

10. Do adolescent females demonstrate "different" problem behaviors than adolescent males? Please describe.

11. Describe the programs your school currently has in place for students with behavior disorders. What type of student is the current program designed for? 
12. Describe your school's current population of students with behavior disorders.

13. Within your school, what is your perceived definition of a student with a behavior disorder?

14. Do you feel as if your school is more likely to classify one type of "problem" behavior than another?

15. What are the support services that exist within your school for students who are experiencing psychological difficulties, but are not referred to special services for having a behavior disorder? 
APPENDLX B

IRB Materials

The University of Rhode Island

Department of Psychology

10 Chafee Road, Suite 8

Kingston, RI 02881

Teachers' Referral Practices for Students With Behavior Disorders CONSENT FORM FOR RESEARCH

Audiotaped Interview

I have been asked to take part in a research project described below. The researcher will explain the project to me in detail. I should feel free to ask questions. If I have more questions later, Nancy Smith, the person mainly responsible for this study, will discuss them with me. Nancy Smith may be reached at 874-4264.

Description of the Project: I have been asked to take part in a study which investigates teachers' referral practices of students with behavior disorders.

What will be done: If I decide to take part in this study, L will be asked to have my interview with the researcher audiotaped. The researcher will audiotape our discussion about teacher's referral processes when referring students to special education for a behavior disorder.

Risks or Discomforts: There are no known risks or discomforts associated with participating in the interview.

Benefits of this Study: Although there will be no direct benefits to me for taking part in this study, the researcher may learn more about teachers' referral practices. Specifically, the researcher may obtain an in-depth understanding of current practices in school settings, and the role the behavior disorder classification currently plays in the special education process.

Confidentiality: My part in this study is confidential. None of the information will identify me by name. In no way will I be identified on the audiotape. All audiotapes will be kept in a locked file cabinet in the researcher's home and will be kept confidential. Transcripts of the interviews will be stored in a locked file cabinet in the researcher's home, will be kept separate from all demographic information, and will be kept confidential. Demographic information will be kept in a locked file cabinet at the University of Rhode Island. Any written report containing individual responses will eliminate information which could potentially identify the respondent. 
Decision to quit at any time: The decision whether or not to take part in this study is up to me. I do not have to participate. If I decide to take part in the study, I may quit at any time. Whatever I decide will in no way penalize me. If I wish to quit I simply inform Nancy Smith (874-4264) of my decision.

If I am not satisfied with the way this study is performed, I may discuss my complaints with Nancy Smith, anonymously, if I choose. In addition, I may contact the office of the Vice Provost for Research, 70 Lower College Road, University of Rhode Island, Kingston, Rhode Island, 02881, telephone: 874-2635.

I have read the Consent Form. My questions have been answered. I agree to have my interview audiotaped. My signature on this form means that I understand the information and I agree to participate in this study.

Signature of Participant

Signature of Researcher

Printed Name

Printed Name

Date

Date 
The University of Rhode Island

Department of Psychology

10 Chafee Road, Suite 8

Kingston, RI 02881

\section{Teachers' Referral Practices for Students With Behavior Disorders CONSENT FORM FOR RESEARCH \\ Interview}

I have been asked to take part in a research project described below. The researcher will explain the project to me in detail. I should feel free to ask questions. If I have more questions later, Nancy Smith, the person mainly responsible for this study, will discuss them with me. Nancy Smith may be reached at 874-4264.

Description of the Project: I have been asked to take part in a study which investigates teachers' referral practices of students with behavior disorders.

What will be done: If I decide to take part in this study, I will be asked to participate in an hour long interview. The information is focused around obtaining information pertaining to teachers' current practices when referring students to special education for a behavior disorder. The interview also explores how teachers perceive the behavior disorder classification within the school system. The interview will be audiotaped, and the information transcribed.

Risks or Discomforts: There are no known risks or discomforts associated with participating in the interview.

Benefits of this Study: Although there will be no direct benefits to me for taking part in this study, the researcher may learn more about teachers' referral practices. Specifically, the researcher may obtain an in-depth understanding of current practices in school settings, and the role the behavior disorder classification currently plays in the special education process.

Confidentiality: My part in this study is confidential. None of the information will identify me by name. In no way will I be identified on the audiotape. All audiotapes will be kept in a locked file cabinet in the researcher's home and will be kept confidential. Transcripts of the interviews will be stored in a locked file cabinet in the researcher's home, will be kept separate from all demographic information, and will be kept confidential. Demographic information will be kept in a locked file cabinet at the University of Rhode Island. Any written report containing individual responses will eliminate information which could potentially identify the respondent. 
Decision to quit at any time: The decision whether or not to take part in this study is up to me. I do not have to participate. If I decide to take part in the study, I may quit at any time. Whatever I decide will in no way penalize me. If I wish to quit I simply inform Nancy Smith (874-4264) of my decision.

If I am not satisfied with the way this study is performed, I may discuss my complaints with Nancy Smith, anonymously, if I choose. In addition, I may contact the office of the Vice Provost for Research, 70 Lower College Road, University of Rhode Island, Kingston, Rhode Island, 02881, telephone: 874-2635.

I have read the Consent Form. My questions have been answered. I agree to have my interview audiotaped. My signature on this form means that I understand the information and I agree to participate in this study.

Signature of Participant

Signature of Researcher

Printed Name

Printed Name

Date

Date 
The University of Rhode Island

Department of Psychology

10 Chafee Road, Suite 8

Kingston, RI 02881

Teachers' Referral Practices for Students With Behavior Disorders

CONSENT FORM FOR RESEARCH

Questionnaire

I have been asked to take part in a research project described below. The researcher will explain the project to me in detail. I should feel free to ask questions. If I have more questions later, Nancy Smith, the person mainly responsible for this study, will discuss them with me. Nancy Smith may be reached at 874-4264.

Description of the Project: I have been asked to take part in a study which investigates teachers' referral practices of students with behavior disorders.

What will be done: If I decide to take part in this study, I will be asked to complete a questionnaire. The questionnaire pertains to which behaviors are indicative of psychological difficulties in students and which behaviors typically lead to special education referrals for behavior disorders. The questionnaire should take about twenty to thirty minutes to complete.

Risks or Discomforts: There are no known risks or discomforts associated with completing the questionnaire.

Benefits of this study: Although there will be no direct benefits to me for taking part in this study, the researcher may learn more about teachers' referral practices. My participation in the study will assist the researcher in understanding teachers' beliefs around behaviors indicative of psychological difficulties, and which behaviors are likely to result in a special education referral for behavior disorders.

Confidentiality: My part in this study is confidential. None of the information will identify me by name. All records will be kept in a locked file cabinet in the researcher's home. All demographic information will be kept in a locked file cabinet at the University of Rhode Island. All written reports will respect participants' confidentiality and will not provide responses with information that could potentially identify the participant.

Decision to quit at any time: The decision whether or not to take part in this study is up to me. I do not have to participate. If I decide to take part in the study, I may quit at any time. Whatever I decide will in no way penalize me. If I wish to quit I simply inform Nancy Smith (874-4264) of my decision. 
If I am not satisfied with the way this study is performed, I may discuss my complaints with Nancy Smith, anonymously, if I choose. In addition, I may contact the office of the Vice Provost for Research, 70 Lower College Road, University of Rhode Island, Kingston, Rhode Island, 02881, telephone: 874-2635.

I have read the Consent Form. My questions have been answered. My signature on this form means that I understand the information and I agree to participate in this study.

Signature of Participant

Signature of Researcher

Printed Name

Printed Name

Date

Date 


\section{BIBLIOGRAPHY}

Achenbach, T.M. (1991). Manual for the teacher's report form and 1991 profile. Burlington, VT: University of Vermont Department of Psychiatry.

Achenbach, T.M., \& Edlebrock, C.S. (1979). The child behavior profile II boys aged 12-16 and girls aged 6-11 and 12-16. Journal of Consulting and Clinical Psychology, 47, 223-233.

Achenbach, T.M., \& Edelbrock, C.S. (1983). Taxonomic issues in child psychopathology. In T.J. Ollendick \& M. Hersen (Eds.), Handbook of child psychopathology (pp. 65-93). New York: Plenum Press.

Achenbach, T.M., \& Edelbrock, C.S. (1981). Behavioral problems and competencies reported by parents of normal and disturbed children aged four through sixteen. Monographs of the Society for Research in Child Development, 46 (Serial No. 188).

Achenbach, T.M., Howell, C.T., Quay, H.C., \& Connors, K.C. (1991). National Survey of problems and competencies among four to sixteen year olds: Parents' reports for normative and clinical samples. Monographs of the Society for Research in child Development, 56 (3, serial No. 225).

Allgood-Merten, B., Lewinsohn, P., \& Hops, H. (1990). Sex differences and adolescent depression. Journal of Abnormal Psychology, 99, 55-63.

Algozzine, B. (1977). The emotionally disturbed child: Disturbed or disturbing? Journal of Abnormal Child Psychology, 5, 205-211.

Algozzine, B. (1980). The disturbing child: A matter of opinion. Behavioral Disorders, $5,112-115$.

Algozzine, B., Christenson, S., \& Yssledyke, J.E. (1982). Probabilities associated with referral-to-placement process. Teacher Education and Special Education, $5,19-23$.

Algozzine, B., Ruhl, K., Ramsey, R., Wood, F., Phillips, V., Maheady, L., Skiba, R., Test, D., Cooke, N., \& Walker, H. (1991). Behaviorally disordered? Assessment for identification and instruction. Working with behavioral disorders, CEC mini-library. Council for Exceptional Children, Reston, VA. Eric reproduction number 333660.

Andrews, J.A., \& Lewinsohn, P.M. (1990). The Prevalence, Lethality and Intent of Suicide Attempts Among Adolescents. Paper presented at the Annual convention of the American Psychological Association, Boston, MA.. 
Bailey, S.M. (1993). The current status of gender equity research in American schools. Educational Psychologist, 28, 321-339.

Barack, R.S. (1986). Hospitalization of emotionally disturbed children: Who gets hospitalized and why? American Joumal of Orthopsychiatry, 56, 317-319.

Barron, P. (1993). Gender differences in the expression of depressive symptoms in middle adolescence: An extension of earlier findings. Adolescence, 28, 903-911.

Bentzen, F. (1966). Sex ratios in learning and behavior disorders. The National Elementary Principal, 46 (2), 13-17.

Berry, C.A., Shaywitz, S.E., \& Shaywitz, B.A. (1985). Girls with attention deficit disorder: A silent minority? Pediatrics, 76, 801-809.

Borko, H., \& Caldwell, J. (1982). Individual differences in teachers' decision strategies: An investigation of classroom organization and management decisions. Journal of Educational Psychology, 74, 598-610. (3), 308.

Bower, B. (1993). Gender paths wind towards self-esteem. Science News, 14

Brooks, B. (1985). Sexually abused children and adolescent identity development. American Journal of Psychotherapy, 32, 401-410.

Brophy, J.E., \& Rohrkemper, M.M. (1981). The influence of problem ownership on teachers' perceptions of and strategies for coping with problem students. Journal of Educational Psychology, 73 , 295-311.

Brown, L.M., \& Gilligan, C. (1992). Meeting at the Crossroads: Women's Psychology and Girls' Development. Cambridge, MA: Harvard University Press.

Brutsaert, H. (1990). Changing sources of self-esteem among girls and boys in secondary schools. Urban Education, 24 (4), 432-439.

Callihan, K. (1994). Wherefore art thou, Juliet? Causes and implications of the male dominated sex ration in programs for students with emotional and behavioral disorders. Education and Treatment of Children, 17 (3), 228-243.

Center, D. (1989). Social maladjustment: Definition, identification, and programming. Focus on Exceptional Children, 22 (1), 1-12.

Clarizio, H.F., \& Higgins, M.M. (1989). Assessment of severe emotional impairment: Practices and problems. Psychology in the Schools, 26, 154-162. 
Cohen, N.J. (1989). Sex differences in child psychiatric outpatients: Cognitive, personality, and behavioral characteristics. Child Psychiatry and Human Development, 20, 113-121.

Compass, B.E. (1987). Stress and life events during childhood and adolescence. Clinical Psychology Review, 7, 275-302.

Council for Children with Behavioral Disorders (1987). Position Paper on Definition and Identification of Students with Behavioral Disorders. Reston, VA: CCBD, a Division of the Council for Exceptional Children.

Council for Children with Behavioral Disorders (1989). White paper on best assessment practices for students with behavioral disorders: Accommodation to cultural diversity and individual differences. Behavioral Disorders, 14, 263-278.

Cramer, P. (1979). Defense mechanisms in adolescence. Developmental Psychology, 15, 476-477.

Cullinan, D., Epstein, M.H., \& Kauffman, J.M. (1984). Teachers' ratings of students' behaviors: What constitutes behavior disorder in schools? Behavioral Disorders, $10,9-19$.

Cullinan, D., Schultz, R.M., Epstein, M.H., \& Luebke, J.F. (1984). Behavior problems of handicapped adolescent female students. Journal of Youth and Adolescence, $13(1), 57-64$.

Cullinan, D., Epstein, M.H., \& Lloyd, J.W., (1983). Behavior Disorders of Children and Adolescence. Englewood Cliffs, NJ: Prentice-Hall.

D'Arcy, C., \& Siddique, C.M. (1984). Psychological distress among Canadian adolescents. Psychological Medicine, 14, 615-628.

de Haas, P. (1986). Attention styles and peer relationships of hyperactive and normal boys and girls. Journal of Abnormal Child Psychology, 14, 457-467.

Dunlop, W.R., \& Dillard, J.W. (1980). Problem behavior from the principal's perception: A new view. Behavioral Disorders, 5, 108-111.

Eme, R.F. (1979). Sex differences in childhood psychopathology: A review. Psychological Bulletin, 86, 574-595.

Eme, R.F. (1984). Sex-role stereotypes and the epidemiology of child psychopathology. In C.S. Widon (Ed.), Sex roles in Psychopathology (pp. 279-316) New York: Plenum Press. 
Epstein, M.J., Kauffman, J.M., \& Cullinan, D. (1985). Patterns of Maladjustment among the behaviorally disordered. II: Boys aged 6-11, boys aged 12-18, girls aged 6-11, and girls aged 12-18. Behavioral Disorders, 10, 125-135.

Gerber, M.M., \& Semmel, M.I. (1984). Teacher as imperfect test: Reconceptualizing the referral process. Educational Psychologist, 12, 137-148.

Gilligan, C. (1982). In a different voice: Psychological theory and women's development. Cambridge, MA: Harvard University Press.

Glavin, G. A., \& Elliott, S.N. (1985). Psychological reevaluations of handicapped children: A survey of practitioners and policymakers. Professional Psychology: Research and Practice, 16, 64-75.

Goldman, R.L. (1990). The educational perspective on abuse. In R. Goldman \& R. Gargiulo (Eds,). Children at risk: An interdisciplinary approach to child abuse and neglect (pp. 37-72). Austin, TX: Pro-Ed.

Goldman, R. L., \& Garguilo, R.M. (1987). Special needs children: A population at risk for sexual abuse. Reading Improvement, 24, 84-89.

Groesnick, J., \& Huntze, S. (1980). National needs analysis in behavior disorders: Adolescent behavior disorders. Columbia, MO: University of Missouri, Department. of Special Education.

Grosenick, J., \& Huntze, S. (1983). National needs analysis in behavioral disorders: Severe behavioral disorders. Columbia, MO: University of Missouri, Department of Special Education.

Guetzloe, E.C., (1993). The special education initiative: Responding to changing problems, populations, and paradigms. Behavioral Disorders, 18 (4), 303-307.

Hallahan, D.P., Keller, C.E., \& Ball, C.W. (1986). A comparison of prevalence rate variability from state to state for each of the categories of special education. Remedial and Special Education, 7, 8-14.

Hauffman, J.M. (1987). Strategies for the nonrecognition of social deviance. British Columbia Journal of Special Education, 11, 201-214.

Hauser, S., Jacobson, A., Noam, G., \& Powers, S. (1983). Ego development and self-image complexity in early adolescence: Longitudinal studies of diabetic and psychiatric patients. Archives of General Psychiatry, 40, 325-332. 
Hayden-Mc Peak, C., Gaskin, S.T., \& Gaughan, L.K. (1993). Bad Boys, Good Girls: A Review of the Research on Gender Differences of Assessment, Child Rearing, and Educational Practice. Paper presented at the Annual convention of The Council for Exceptional Children, San Antonio, TX.

Henker, B., \& Whalen, C.K. (1989). Hyperactivity and attention deficits. American Psychologist, 44, 216-223.

Hill, J.P., \& Lynch, M.E. (1983). The intensification of gender-related role expectations during early adolescence. In Brooks-Gunn, J. and Peterson, A.C. (Eds), Girls at Puberty: Biological and Psychosocial Perspectives. Plenum: New York.

Holland, R.P. (1980). An analysis of the decision-making process in special education. Exceptional Children, 46, 551-554.

Horn, W.F., Wagner, A.E., \& Ialongon, N. (1989). Sex differences in school-aged children with pervasive attention deficit hyperactivity disorder. Journal of Abnormal Child Psychology, 17, 109-125.

Hutton, J.B. (1985). What reasons are given by teachers who refer problem behavior students? Psychology in the Schools, 22, 79-82.

Jennings, K.D., Mendelsohn, S.R., May, K., \& Brown, G.M. (1988). Elementary students in classes for the emotionally disturbed: Characteristics and classroom behavior. American Joumal of Orthopsychiatry, 58, 65-76.

Kashani, J., Chapnel, J.L., Ellis, J., \& Shekim, W.O. (1979). Hyperactive Girls. Joumal of Operational Psychiatry, 10, 145-148.

Kauffman, J.M. (1986). Educating children with behavior disorders. In R.J. Morris \& B. Blatt (Eds.), Special education: Research and trends (pp. 249-271). New York: Permagon Press.

Kauffman, J.M. (1989). Characteristis of behavior disorders of children and youth (4th ed). Columbus, OH: Merrill.

Kauffiman, J.M., McCullogh, L.L., \& Sabornie, E.J. (1984). Integrating exceptional students: Special problems involving the emotionally disturbed/ behaviorally disordered. British Columbia Joumal of Special Education, 8, 201-210.

Kauffman, J.M., Swan, W.W., \& Wood, M.W. (1980). Do parents, teachers, and psycho-educational evaluators agree in their peceptions of black and white emotionally disturbed? Psychology in the Schools, 17, 185-191. 
Kauffman, J.M., Cullinan, D., \& Epstein, M. (1987). Characteristics of students placed in programs for the seriously emotionally disturbed. Behavioral Disorders, 42 , 175-184.

Kavale, K., Forness, S., \& Alper, A. (1986). Research in behavioral disorders/emotional distrubance. A survey of subject identification criteria. Behavioral Disorders, 43, 159-167.

Keleman, L. (1987). The Impact of Teacher and Student Variables in Predicting Referral to Special Education. Paper presented at the Annual Meeting of the american Educational Research Associaltion (Washington, D.C., April 20-24, 1987). ED 287241 Ec 200546

Kornblau, B. (1982). The teachable pupil survey: A technique for assessing teachers' perceptions of pupil attributes. Psychology in the Schools, 19, 170-174.

Kornblau, B., \& Keogh, B.K. (1980). Teachers' perceptions and educational decisions. New Directions for Exceptional Children, 1, 87-101.

Lavitt, M.R. (1993). The influence of gender on the self-perception of disturbed children. Child and Adolescent Social Work Journal, 9 (3), 221-237.

Lindrow, J., Marrett, G.B., \& Wilkinson, L.C. (1985). Gender influences in classroom behavior. Orlando: Florida: Academic Press.

MacFarlane, J., Allen, L., \& Honzik, M. (1954). A developmental study of the behavior problems of normal children between 21 months and 14 years. Berkeley: University of California Press.

Marsh, D.T., Stoughton, N.L., \& Williams, T.A. (1985). Effects of role, gender, age, and parental status on perception of childhood problems. Exceptional Children, 52 , 170-177.

Martin, R. (1972). Student sex and behavior as determinants of the type and frequency of teacher- student contacts. Journal of School Psychology, 10, 339-347.

Mattison, R.E., Humphrey, F.J., Kales, S.N., \& Wallace, D.J. (1986). An objective evaluation of special class placement of schoolboys with behavior problems. Journal of Abnormal Child Psychology, 14, 251-262.

Mattison, R.E., Morales, J., \& Bauer, M.A. (1991). Elementary and secondary socially and/or emotionally disturbed girls: Characteristics and identification. Journal of School Psychology, 22, 121-134. 
Mattison, R.W., Humphrey, F.J., Dales, S.N., Handford, H.A., Finkenbinder, R.L., \& Hermit, R.C. (1986). Psychiatric background and diagnoses of children evaluated for special class placement. Journal of the American Academy of Child Psychiatry, 25. 514-520.

McConaughy S., \& Achenbach, T. (1989). Empirically based assessment of serious emotional disturbance. Journal of School Psychology, 26, 91-117.

McGee, R, \& Feehan, M. (1991). Are girls with problems of attention unrecognized? Journal of Psychopathology and Behavioral Assessment, 13 (3), 187-198.

McGee, R., Williams, S.M., \& Silva, P.A. (1987). A comparison of girls and boys with teacher-identified problems of attention. Journal of the American Academy of Child and Adolescent Psychiatry, 26, 711-717.

McGinnis, E., Kiraly, J., \& Smith, C.R. (1984). The types of data used in identifying public school students as behaviorally disordered. Behavioral Disorders, 2 . 239-246.

McGuire, M.D., \& Goldman, RL., (19 ). Targets for abuse: Children and youth with behavioral disorders. In Braaten, S.L. \& Wild, E. (Eds.). Programming for children with behavioral disorders: Volume 5 (p. 21-33). Council for Children with Behavioral Disorders.

Mc Intyre, L.L. (1990). Teacher standards and gender: Factors in special education referral? Journal of Educational Research, 83, 166-172.

Meir, J., \& Sloan, M. (1984). The severely handicapped and child abuse. In J. Blacher (Ed.). Severely handicapped young children and their families (pp. 247-272). San Diego: Academic Press, Inc.

Mendelsohn, S.R., \& Jennings, K.D. (1986). Characteristics of emotionally disturbed children referred for special education assessment. Child Psychiatry and Human Development, 16 (3) 154-170.

Meyer, C.J., \& Foster, S.F. (1988). The effect of teacher self-efficacy on referral chance. Journal of Special Education, 22, 378-85.

Miles, M.B., \& Huberman, A.M. (1994). Qualitative Data Analysis. Thousand Oaks, CA: Sage.

Miller, D., Trapani, C., Fejes-Mendoza, K., Eggleston, C., \& Dwiggins, D. (1992). Females with emotional and behavioral disorders: Unique considerations. Paper presented at the annual Conference of Teacher Educators for Children with Behavioral Disorders, Phoenix, AZ, November 19-21, 1992. Ed 361971. 
Miller, D. (1993). Adolescents with behavioral/emotional disorders: Gender issues in suicidal behavior. British Columbia Journal of Special Education, 17, 148-160.

Miller, D. (1993). Sexual and physical abuse among adolescents with behavioral disorders: Profiles and implications. Behavioral Disorders, 18 (2), 129-138.

Miller, L.C. (1972). School Behavior Checklist: An inventory of deviant behavior for elementary school children. Journal of Counseling and Clinical Psychology, 38 , 134-144.

Mooney, C., \& Algozzine, B. (1978). A comparison of the distrubingness of LD and ED behaviors. Journal of Abnormal Child Psychology, 6, 401-406.

Morse, W.C., Cutler, R.L., \& Fink, A.H. (1964). Public school classes for the emotionally handicapped:A research analysis. Washington, DC: Council for Exceptional Children, NEA.

Mullen, J.A, \& Wood, F.H. (1986). Teacher and student ratings of the disturbingness of common problem behaviors. Behavioral Disorders, 11 , 168-176.

Noam, G.G., \& Boarst, S. (1994). Developing meaning, losing meaning: Understanding suicidal behavior in the young. New Directions for Child Research, 64 . 39-54.

Noel, M. (1982). Public school programs for the emotionally disturbed: An overview. In M. Noel and N. Haring (Eds.). Progress or change: Issues in educating the emotionally disturbed (Vol 2). Seattle: University of Washington.

Nolen- Hoeksma, S. (1987). Sex differences in unipolar depression: Evidence and theory. Psychological Bulletin, 101, 259-282.

Olsen, L.J., \& Holms, W.M. (1986). Youth at risk: Adolescents and maltreatment. Children and Youth Services Review, 8, 13-35.

Offord, D.R., Boyle, M.H., Szatmari, P., \& Grant, N.I. (1987). Ontario Child health study: II. Six month prevalence of disorder and rates of service utilization. Archives of General Psychiatry, 44, 832-836.

Orr, D.P., \& Downes, M.C. (1985). Self-concept of adolescent sexual abuse victims. Joumal of Youth and Adolescence, 14, 401-410.

Packer, M.J., \& Addison, R.B. (1989). Introduction. In M.J. Packer \& R.B. Addison (Eds.), Enterning the circle: Hermeneutic investigation in psychology (pp 13-36). Albany: State University of New York. 
Paul, J.L. (1985). Where are we in the education of emotionally disturbed children? Behavioral Disorders, 9 239-246.

Pearcy, M.T., Clopton, J.R., \& Pope, A.W. (1993). Influences on teacher referral of children to mental health services: Gender, severity, and internalizing versus externalizing problems. Journal of Emotional and Behavioral Disorders, 1 165-169.

Peterson, A.C. (1979). Female Pubertal Development. In Sugar, M. (Ed.), Female adolescent development: Brunner/Mazel, New York.

Petersen, A., Sarigiani, P., \& Kennedy, R. (1991). Adolescent depression: Why more girls? Joumal of Youth and Adolescence, 20 (2), 247-271.

Quay, H.C. (1977). Measuring dimensions of deviant behavior: The Behavior Problem Checklist. Journal of Abnormal Child Psychology, 5, 277-287.

Redmore, C., \& Loevinger, J. (1979). Ego development in adolescence: Longitudinal studies. Journal of Youth and Adolescence, 8, 1-20.

Rhodes, W.C. (1967). The disturbing child: A problem of ecological management. Exceptional Children, 33, 444-455.

Rhodes, W.C. (1970). A community participation of aalysis of emotional disturbance. Exceptional Children, 36, 309-314.

Rhodes, W.C., \& Paul, J.L. (1978). Emotionally disturbed and deviant children. Englewood Cliffs, New Jersey: Prentice Hall.

Riffle, C.A. (1985). Factors influencing regular classroom teachers' referral practices. Teacher Education and Special Education, 8 (2), 66-74.

Russel, D.E.H. (1983). The incidence and prevalence of intrafamilial and extrafamilial sexual abuse of female children. Child Abuse and Neglect, 7, 133-146.

Rutter, M. (1986). The developmental psychopathology of depression: Issues and perspectives. In M. Rutter, C. Ixartd \& P. Read (Eds.) Depression in young people: developmental and clinical perspectives. (pp 3-30). New York: Guilford.

Schacer, R., Sandberg, S., \& Rutter, M. (1986). Agreement between readers" ratings and observations of hyperactivity, inattentiativeness, and defiance. Journal of Abnormal Child Psychology, 14, 331-345.

Schultz, D. (1991). Risk, resiliency and resistance: Current research on adolescent girls. New York: MS foundation for Women National Girls Initiative. 
Serbin, L.A., OLeary, K.D., Kent, R.N., \&Tonick, I.J. (1973). A comparison of teacher response to preacademic and problem behavior of boys and girls. Child Development, 44, 796-804.

Shinn, M. (1987). Special education referrals as an index of teacher tolerance: Are teachers imperfect tests? Exceptional Children, 54, 32-40.

Siegel, S. (1956). Nonparametric statistics for the behavioral sciences. New York: McGraw-Hill.

Smith, C., Frank, A., \& Snider, B.C.F. (1984). School psychologists and teachers' perception of data used in the identification of behaviorally disordered students. Behavioral Disorders, 10, 27-32.

Siddique, C.M., \& D'Arcy, C. (1984). Adolescence, stress, and psychological well-being. Journal of Youth and Adolescence, 13, 459-473.

Stephens, B.J. (1987). Cheap thrills and humble pie: The adolescence of female suicide attempters. Suicide and Life Threatening Behavior, 17 (2), 107-118.

Strelniek, M., \& Wessel, J. (1993). Assessment Practices of School Psychologists When Identifying children for SED classes. Paper presented at the Annual convention of the National Association of School Psychologists. Washington, D.C., pp 13-17. Eric reproduction number 370281 .

Stockard, J. (1980). Sex iinequities in the experience of students. In J. Stockard, P.A. Schmuck, K. Kempner, P. Williams, S.K. Edson \& M.A. Smith (Eds.). Sex equity in education. (pp 11-48). New York: Academic Press.

Thorne, B. (1993). Gender play: Girls and boys in school. New Brunswick, NJ: Rutgers University.

U.S. Department of Education (1988). Elementary and Secondary School Civil Rights Survey. Office of Civil Rights: Washington, DC.

U.S. Department of Education (1990). Individuals with Disabilities Education Act. Washington, DC.

U.S. Department of Education. (1992). Eourteenth annual report to congress on the implementation of the Individuals with Disabilities Education Act Washington, DC: Office of Special Education and Rehabilitative Services. 
Van-Gijseghem, H., \& Gautheri, M.C. (1994). Links between sexual abuse in childhood and behavioral disorders in adolescent girls: A multivariate approach. Canadian Journal of Behavioral Science, 26 (3), 339-352.

Verhulst, F.C. \& Akkerhuis, G.W. (1989). Agreement between parents' and teachers' ratings of behavioral/emotional problems of children aged 4-12. Journal of Child Psychology and Psychiatry, 30, 123-136.

Vitale, M.R. (1983). Using multidimensional scaling and unfolding to explore teacher perceptual biases for selecting special education referral strategies. Journal of Experimental Education, 51, 134-41.

Walker, H.M., \& Fabre, T.R. (1987). Assessment of behavior disorders in the school setting: Issues, problems, and strategies revisited. In N. Haring (Ed.), Assessing and managing behavior disabilities (pp 198-246). Seattle: University of Washington Press.

Walker, C.E., Bonner, B.L., \& Kaufman, K.L. (1988). The physically and sexually abused child. New York: Pergamon.

White, R., Beattie, J., \& Rose, T. (1985). A survey of state definitions of behavioral disorders: Implications for adolescent programming. In S. Braaten, R.J. Rutherford Jr., \& W. Evans (Eds.) Programming for Adolescents with Behavioral Disorders: Volume II. (p 118-126). Reston, VA: Council for Exceptional Children, Division for Children with Behavioral Disorders.

Widman, K. (1992). Differences in adolescents' self concept as a function of academic level, ethnicity, and gender. American Journal of Mental Retardation, 96, 387-404.

Wood, F.H. (1981). The influence of personal, social, and political factors on the labeling of students. In F.H. Wood (Ed.), Perspectives for a new decade (pp. 45-62). Reston, VA: Council for Exceptional Children.

Wood, F.H. (1985). Issues in the identification and placement of behaviorally disordered students. Behavioral Disorders, 10, 219-228.

Wood, J. (1981). Perspectives for a New Decade: Education's Responsibility for Seriously Disturbed and Behavior Disordered Children and Youth. CEC/CCBD National Topical Conference on the SED. August 13-15, Minneapolis, MN.

Woolfolk, R.L., Sass, L.A. \& Messer, S.B. (1988). Introduction to hermeneutics. In R.L. Woolfolk, L.A. Sass \& S.B. Messer (Eds.), _Hermeneutics and psychological theory: Interpretive perspectives on personality, psychotherapy, and psychopathology, (pp. 2-26). New Brunswick: Rutgers University Press. 
Ysseldyke, J., \& Thurlow, M. (1984). Assessment practices in special education: Adequacy and appropriateness. Educational Psychology, 9, 123-136. 